\title{
LOS MONSTRUOS MARINOS DE ERIK PONTOPPIDAN. TRADUCCIÓN \\ ESPAÑOLA DE NATURAL HISTORY OF NORWAY(1755) PART II, CHAPTER VIII, “CONCERNING CERTAIN SEA-MONSTERS, OR STRANGE AND UNCOMMON SEA-ANIMALS" Arturo Morgado García y JoAQuín Ritoré PonCE UNIVERSIDAD DE CÁDIZ
}

En 1555 se publicaba en Roma la Historia de Gentibus Septentrionalibus, del clérigo sueco Olao Magno. Esta obra gozó de un impacto extraordinario en su momento, y vendría a significar el principio de una larga saga dedicada a los monstruos marinos, siendo repetida, copiada e imitada hasta la saciedad, tanto en su texto como en sus ilustraciones. En la segunda mitad del siglo XVII, sin embargo, su influencia sobre los medios académicos comienza ya desvanecerse, ya que la ingenuidad y la credulidad del autor no constituían, precisamente, las mejores cartas de presentación en un momento en que comienza a manifestarse una gran preocupación por la busca de testigos cualificados y de criterios de verificación ${ }^{1}$, puntos fundamentales de ese nuevo modelo de conocimiento al que damos en llamar Revolución cientifica. Sin embargo, en 1752 aparecía en Copenhague Det forste Forsog paa Norges naturlige Historie, que sería traducida al inglés tres años más tarde como la Natural History of Norway, y que contribuiría a revitalizar el venerable género literario de los monstruos marinos, enriqueciendo incluso su acerbo con una nueva criatura, el kraken.

Erik Pontoppidan ${ }^{2}$ nació en la localidad danesa de Arhus en 1698, falleciendo en Copenhague en 1764. Tras estudiar teología en la universidad de Fredericia, y realizar diversos viajes por Europa, concretamente a Inglaterra y las Provincias Unidas (lo que le permitiría familiarizarse con lenguas como el inglés y el francés), seguiría su carrera como pastor de la iglesia luterana (que era la Iglesia estatal en Dinamarca), manteniendo unos lazos muy estrechos con el pietismo ${ }^{3}$, comenzaría sus actividades como profesor universitario en 1738 ,

\footnotetext{
${ }^{1}$ SHAPIN, Steven: A social history of truth, University of Chicago Presss, 1994. SHAPIN, Steven, y SCHAFFER, Simon: Leviathan and the air pump. Hobbes, Boyle and the experimental life, Princeton U.P. 1985, reed. 2011.

${ }^{2}$ No nos consta que haya algún estudio reciente sobre Pontoppidan en un idioma asequible para los hispanohablantes. Habrá que acudir a HOFMAN, Niels Erik: Prokantsler Erik Pontoppidans Levnetsbeskrivelse og hans Dagbog fra en Reise i Norge i Aaret 1749, Hempel, 1874. Una biografía rápida en DANKAER, David M.: The Copepodologist's Cabinet: A Biographical and Bibliographical History (Memoirs of the Americal Philosophical Society, número 240), vol. 1, 2002, pp. 37-38.

${ }^{3}$ La referencia clásica sobre Pontoppidan y el piestismo es NEIIENDAM, Michael: Erik Pontoppidan: studier og bidrag til pietismens historie, 2 vols., Copenhague, Gads Forlag, 1930-33. Más reciente, HORSTBOLL, Henrik: "Pietism in Denmark-Norway in the Eighteenth Century: The Discourse of Erik Pontoppidan", en VAN LIEBURG, Fred, y LINDMARK, Daniel: Enlightenment and Pietism, revivalism and modernity, Newcastle, Cambridge Scholars, 2008.
} 
y sería nombrado obispo de Bergen, en Noruega (por aquel entonces, y hasta el congreso de Viena, propiedad danesa), siete años más tarde, aunque regresaría a Dinamarca en 1754. Su producción erudita es muy amplia, abarcando tanto la historia y las antigüedades (Theatrum Daniae veteris et modernae, Bremen, 1730), como la filología (Glossarium Norvagicum, Bergen, 1749), como la geografía (Den danske Atlas, Copenhague, 1763-67) ${ }^{4}$, aunque si se hubiera limitado a estos intereses nada habría podido impedir que hubiera pasado a la historia como un oscuro erudito dieciochesco más, siendo, con gran diferencia, su Natural History of Norway la que le ha convertido en un autor relativamente conocido, al menos en los medios académicos, fuera de su país natal, hasta el punto de que dicha obra tan sólo tres años después de su publicación trascendió las fronteras del mismo para ser traducida al inglés (no debe ser una casualidad, habida cuenta de los fuertes lazos comerciales existentes por entonces entre Gran Bretaña y Escandinavia, sobre todo a través de los puertos del norte de la isla), siendo la traducción inglesa, naturalmente, la que es conocida universalmente. Algún académico contemporáneo ha llegado a denominarle "el Plinio noruego", debido a la variedad de sus capítulos sobre geografía, geología, flora, o fauna de la región ${ }^{5}$.

A pesar de la heterogeneidad de cuestiones abordadas en la Natural History of Norway, es el capítulo 8 de la segunda parte de la misma, dedicado a los monstruos marinos, con gran diferencia, el más leído y consultado en la actualidad. Aquí nos encontramos con criaturas ya conocidas por la Historia Natural del momento, como las sirenas o las serpientes marinas, así como la referencia a un nuevo ser extraído de los mitos escandinavos, a saber, el kraken, y todo ello ha hecho hasta la actualidad las delicias de los criptozoólogos, que con frecuencia acuden a la obra de Pontoppidan para fundamentar sus más o menos delirantes teorías, siendo éste el caso de Antoon Cornelis Oudemans ${ }^{6}$, Rick Emmer ${ }^{7}$, o Daniel Loxton ${ }^{8}$, sin olvidar las muy conocidas alusiones que encontramos en la literatura del siglo XIX, como el poema del mismo título (1830) de Alfred Tennyson (y que contribuyó a popularizar la imagen de esta criatura en el mundo anglosajón), Moby Dick (1851) de Herman Melville, o Veinte mil leguas de viaje submarino (1869) de Julio Verne, o las incesantes ocasiones en las que sus

\footnotetext{
${ }^{4}$ BUNTING, B.T.: "Pioneer observations on soil formation and environment in Scandinavia: Erik Pontoppidan (1698-1764): His Danish Atlas of 1763 and his Natural History of Norway (1752)", Advances in Geoecology, 290 (1997).

${ }^{5}$ DANKAER, David M.: op. Cit., p. 37.

${ }^{6}$ OUDEMANS, Antoon Cornelis: The Great Sea Serpent, reed., Nueva York, Cossimo Classics, 2008.

${ }^{7}$ EMMER, Erick: Kraken: Fact Or Fiction?. Nueva York, Infobase Publishing, 2010.

${ }^{8}$ LOXTON, Daniel, y PROTHERO, Ronald R.: Abominable Science: Origins of the Yeti, Nessie, and other Famous Cryptids, Columbia University Press, 2013.
} 
observaciones fueron copiadas impunemente por la prensa decimonónica. Incluso en España la obra de Pontoppidan fue conocida muy pronto, por cuanto en 1800 ya encontramos una referencia a sus monstruos marinos en El viajero universal ${ }^{9}$.

Pero seríamos injustos si considerásemos a Pontoppidan un autor crédulo o acrítico ${ }^{10}$. Una lectura detenida sobre su capítulo dedicado a los monstruos marinos nos revela una gran preocupación por la veracidad de las fuentes, así como la búsqueda continua de testigos cualificados que puedan proporcionar noticias de primera mano y que hayan observado los fenómenos directamente ${ }^{11}$, distinguiendo con frecuencia entre lo que considera posible y lo que define como una mera fábula, en el sentido de fabuloso o fantástico que le dieran los autores de la Ilustración ${ }^{12}$. Al fin y al cabo, no podemos olvidar que la discusión sobre los monstruos marinos, si tomamos como ejemplos el pez monje y el pez obispo, sirvió para que los eruditos de la época se tomaran la molestia de contrastar unas fuentes de información de procedencia muy diversa ${ }^{13}$.

Pontoppidan se muestra además como un autor muy leído, buen conocedor de la Biblia, dado su condición de pastor luterano, de los autores clásicos, especialmente el inefable Plinio, de la erudición escandinava, comenzando por el Speculum Regale del siglo XIII y por Olao Magno (a quien considera demasiado crédulo), y culminando con los académicos nórdicos de los siglos XVII y XVIII, y, por supuesto, de la producción europea, como revelan las referencias a Konrad Gesner, Guillaume Rondelet, Athanasius Kircher, o Kaspar Schott, si bien esta erudición libresca no impedirá, aunque ello no sea ni mucho menos una contradicción, continuas referencias a la divinidad, a la diversidad de su obra, y a su continua providencia.

Dado que, al menos que sepamos, no existe ninguna traducción al español de la obra de Pontoppidan, ofrecemos la versión en castellano del capítulo más llamativo de la misma, a saber, el dedicado a los monstruos marinos, y que podemos encontrar en la segunda parte de la Natural History of Norway. Aunque existen ediciones recientes de la obra ${ }^{14}$, hemos optado

\footnotetext{
9 ESTALA, Pedro: El viajero universal, o Noticia del mundo antiguo y nuevo, Madrid, Imprenta de Villalpando, volumen XXXI, pp. 139-140.

10 Una discusión al respecto en BRENNA, Brita: "Natures, Contexts and Natural History”, Science, Technology, \& Human Values, Vol. 37, No 4 (2012), pp. 355-378, especialmente pp. 370-371.

${ }^{11}$ El valor de la observación como criterio de verificación en DASTON, Lorraine: "The empire of observation 1600-1800", en DASTON, Lorraine, y LUNBECK, Elizabeth: Histoires of scientific observation, University of Chicago Press, 2011.

${ }^{12}$ ROBBINS, Louise E.: Elephant slaves and pampered parrots. Exotic animals in Eighteenth Century Paris, The John Hopkins University Press, 2002.

${ }^{13}$ MACKENZIE, Louisa: "French Early Modern Sea-Monsters and Modern Identities", en Pia F. CUNEO, Animals and Early Modern Identity, Ashgate, 2014.

${ }^{14}$ Por ejemplo, una edición de bolsillo publicada por Gale Ecco, Print Editions en el 2010.
} 
por consultar directamente la primera edición inglesa. Los números que aparecen en el texto entre paréntesis se refieren al número de página de la edición inglesa de 1755.

\section{ERICH PONTOPPIDAN, THE NATURAL HISTORY OF NORWAY, PART II}

Londres, A. Linde, 1755

Capítulo VIII. Sobre ciertos monstruos marinos, o extraños y poco comunes animales

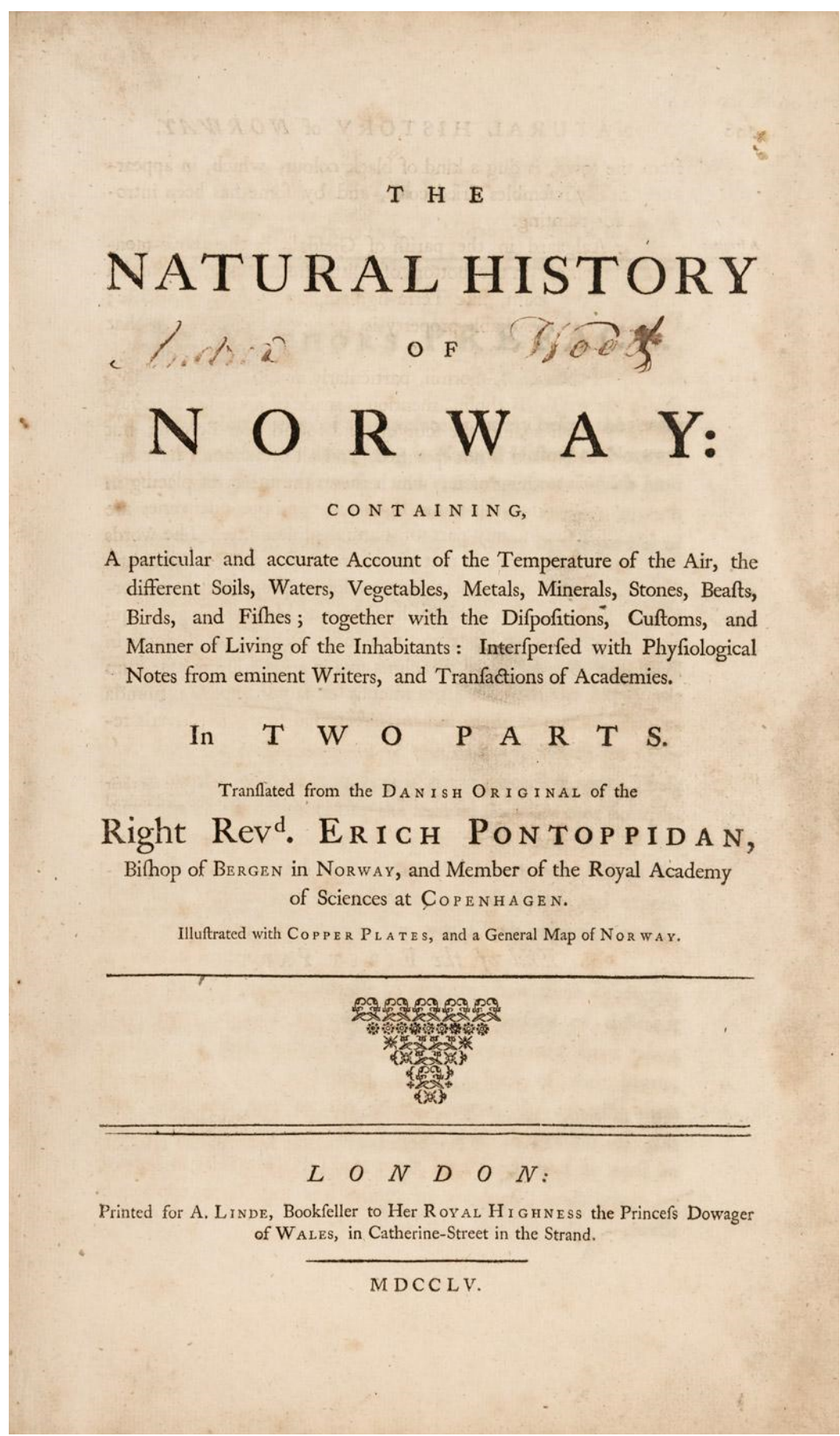

Imagen 1. Portada de la edición inglesa de 1755

https://books.google.es/books?id=3OglUqRf_soC\&printsec $=$ frontcover\&hl=es $\# \mathrm{v}=$ onep age\&q\&f=false 


\section{Sección I. Algunos habitantes del Océano son difíciles de ser conocidos con algún grado de certeza, y debemos establecer un límite razonable en nuestra opinión acerca de ellos.}

En los tres capítulos precedentes he tratado de los peces, y otros animales encontrados en los mares de Noruega, tanto como he sido capaz de trazar su historia por una extensa correspondencia, y por conversar frecuentemente con algunos observadores curiosos de las cosas de la naturaleza, incluyendo los descubrimientos que he sido capaz de hacer por mí mismo en varias ocasiones. He sido incapaz de proseguir este trabajo con alguna exactitud, por los muchos especímenes de diferentes animales marinos, frescos, secos, o conservados en alcohol, que han venido a mis manos. Aunque el número de estos especímenes sea muy grande, excediendo el centenar de diferentes especies, todavía, sin embargo, son una muy pequeña parte de los habitantes del océano $(183)^{15}$, así que podemos unirnos al Salmista en su piadosa exclamación “¡Cuán numerosas tus obras, Yahveh! Todas las has hecho con sabiduría, de tus criaturas está llena la tierra. Ahí está el mar, grande y de amplios brazos, y en él el hervidero innumerable de animales, grandes y pequeños" ${ }^{\prime 16}$. No sólo su número inabarcable, sino también su variedad, excede con mucho, por lo que podemos juzgar, las especies de animales terrestres.

La dificultad de conocerlos todos. El elemento en el cual estos últimos respiran, denominado el aire, no permite que se oculten por mucho tiempo, o sean ignorados por la humanidad, así que, suponiendo incluso que sean escasos, deben haber sido vistos alguna vez por los hombres, y, en consecuencia, ser conocidos en alguna medida. Pero, ¿quién hay que viva con aletas en lo más hondo del océano?, o ¿quién tiene la oportunidad de observarlos exacta y familiarmente, en ese inestable y bullicioso elemento? Esto es verdad, gran número de diferentes clases de peces, a los cuales el benéfico Creador, con cuidado más que paternal,

\footnotetext{
${ }^{15}$ Los nombres de todos los animales que viven en las aguas son ciento cuarenta y cuatro según Isidoro. Para Jerónimo, en cambio, son ciento cincuenta y tres, y esto es también lo que afirman los autores de tratados sobre pesca (balieutiká), entre los que se encuentra Opiano de Cilicia, etc. Pero hasta hoy no he leído a nadie que llegue exactamente a esta cifra. Antes de Opiano, Plinio había enumerado ciento veinticuatro especies de animales que viven en el mar, y el catálogo de Plinio lo engrosaron enormemente los que han escrito sobre esta materia en nuestro tiempo, etc. Añado lo que añade el propio Opiano, a saber, que hay muchas cosas ocultas en el mar: $y$ de estos secretos ningún mortal podría hablar (Opiano, Haliéutica I 86-87). Más aún, si creemos a Mahoma, según AlDamiri en el capítulo sobre las langostas, Dios creó mil especies de animales, de las cuales hay seiscientas en el mar y cuatrocientas en la tierra. Y más generosos que el falso profeta son los autores del Talmud, quienes fijan en setecientas tan solo las especies de peces puros, en lo cual no habría exageración alguna si por "peces puros" entendieran criaturas acuáticas en general. Gesnerus, en efecto, muestra más de setecientos nombres e imágenes de animales acuáticos. A nosotros nos basta con haber mencionado aquí los géneros más importantes. Samuel Bochart, Hierozoicon lib. I, cap. VI, p. 37(En latín en el original) (Nota del autor).

16 Salmo 104, 24-25. Todas las traducciones de la Biblia han sido tomadas de la Biblia de Jerusalén (edición 1976).
} 
ha dispuesto como comida para la humanidad, obedeciendo su mandato de visitarnos como a invitados bienvenidos, o se reúnen en nuestras costas, en ciertas estaciones del año, como si nos ofrecieran su servicio. Junto a estas especies que son útiles para el hombre, hay otras que son inútiles o dañinas, que han sido creadas, indudablemente, con algún prudente propósito: éstas muestran a nuestra vista su enorme tamaño, o sus toscas formas, y caen víctima del hombre, por caer involuntariamente en trampas preparadas para otras de la tribu escamosa de un tipo más beneficioso. Nuestros pescadores tiran muchas de estas especies poco comunes directamente al mar, considerándolas no sólo inútiles, sino ominosas, y las denominan con el nombre general de Trold-fisk, o pez infausto ${ }^{17}$. Este procedimiento, como ha sido observado antes, parte de una noción supersticiosa (184), muy perjudicial para el estudio de la naturaleza, porque los pescadores están convencidos de que si los preservan, encontrarán pleno éxito en sus pesquerías. O algo menos de desgracia. Sin embargo, de los pocos que han caído accidentalmente en nuestras manos, aunque no sean suficientes para nuestro propósito, se puede aprender alguna idea de la forma del resto. Si fuera posible penetrar a través del espeso medio acuático, como lo hacemos en el aire, veríamos objetos maravillosos, de acuerdo con los relatos dados por quienes están empleados en recoger cosas naufragadas. Estos hombres, si uno es capaz de creerles, ven extrañas formas en las profundidades más hondas del mar, que difícilmente otros ojos han visto. Si fuera posible que el mar pudiese ser desecado de sus aguas, y vaciado por algún extraordinario accidente, $i$ qué increíble número, qué infinita variedad de poco comunes y sorprendentes monstruos marinos aparecerían a nuestra vista, que nos son enteramente desconocidosi Tal visión nos hará de una vez determinar la verdad de muchas hipótesis concernientes a los animales marinos, cuya existencia es disputada y vista incluso como quimérica.

\section{Somos proclives a creer algunas cosas demasiado, y otras demasiado poco.}

Concederé que puedan ser inciertos, porque tenemos muy pocas oportunidades de

\footnotetext{
${ }_{17}$ En el año 1744 un tal Dagfind Korsbeck capturó, en la parroquia de Sundelvems o Sundmoer, un pez monstruoso, que muchas personas vieron en esta casa. Su cabeza era casi como la de un gato, tenía cuatro garras, sin cola, y alrededor del cuerpo un duro caparazón, como del de una langosta, ronroneaba como un gato, y cuando ponían un palo junto a él, lo rompía. Los campesinos lo consideraron como un Trold, o pez ominoso, y tenían miedo de conservarlo, y, por consiguiente, algunas horas más tarde lo arrojaron nuevamente al mar. De acuerdo a su descripción, puede ser llamado armadillo marino, por cuyo nombre es conocido un animal americano, casi de la misma forma, exceptuando que tiene una larga cola. Un pescador en Sundland, a dos millas de Bergen, me contó que él había visto un monstruo marino mucho más sorprendente junto a su barca, y justamente tras echar un vistazo a su barca de pesca, se hundió inmediatamente bajo el agua. No era diferente a un ternero de mar, y tenía una piel peluda. El cuerpo era tan ancho y grande como el de un bajel de 50 lasts de grueso, y la cola, que parecía ser de cerca de seis brazas de largo, era bastante delgada, y puntiaguda al final. Hay un informe, pero no del todo fiable, según el cual algunos campesinos de Sundmoer han capturado una serpiente en una red, la cual era de tres brazas de largo, y tenía cuatro piernas, debiendo ser parecida a un cocodrilo. Los campesinos huyeron asustados, y dejaron que la serpiente hiciera lo mismo (Nota del autor).
} 
determinar este punto, ni evidencias tan claras que no dejen lugar a dudas, pero al mismo tiempo es verdad que no debemos ser demasiado crédulos, y creer los vanos cuentos y las improbables historias que cuentan muchos pescadores y marineros, ya sea por dar crédito a uno de sus compañeros, o por lo que han visto ellos mismos, cuando están embellecidas con muchos añadidos y variaciones, concernientes a extraños y horribles monstruos marinos. Soy de la opinión de que el extremo opuesto se aleja un tanto de la verdad, esto es, cuando no creemos cosas extrañas o poco comunes, aunque, de acuerdo con las inmutables leyes de la naturaleza, posibles, porque no podemos tener evidencias y clara demostración de ello. Según este argumento, todos los hechos históricos deberían ser destruidos. Uno puede dudar si hay hotentotes ${ }^{18}$, porque aunque el número de testigos sea mucho más grande en ese caso, no altera la naturaleza del conocimiento, solamente proporciona un mayor grado de certeza. Presumo esto como innegable, no sin causa (185), porque me he propuesto en este capítulo, como muestra de la sabiduría, poder y gloriosa economía del Creador, dar cuenta de los monstruos marinos que se han encontrado en el océano, a lo largo de las costas de Noruega. Aunque éstos no aparecen todos los días, han sido vistos bastante a menudo para nuestro propósito, hay muchos testigos de crédito y reputación que los han visto, incluso centenares pueden ser presentados para cada ejemplo, si ello fuera requerido.

Hay muchas cosas pertenecientes a la Historia Natural de Noruega que son comunes en otros lugares, aunque, quizás, poco frecuentes para nosotros, aquí hay también muchas cosas comunes y bien conocidas en este país, que, en otros lugares, pueden ser puestas en duda. Estas consideraciones fueron los principales motivos que me movieron a emprender este molesto, y, en muchos sentidos, difícil trabajo.

\section{Sección II. Sobre el $\mathrm{Hav}$-Strambe y Maryge, o sireno ${ }^{19}$ y sirena, cuyos relatos son a menudo, aunque no siempre, fabulosos.}

Hav-Mand, Mer-man. Entre los muchos monstruos marinos que hay en el mar del Norte, y que han sido vistos a menudo, daré el primer lugar al Hav-Manden, o sireno, cuya compañera es denominada Hav-Fruen, o sirena.

\footnotetext{
18 Si solamente se creen las cosas que se han visto, no habría nada de cierto en la historia. Los tribunales de justicia no podrían pronunciarse sobre las deposiciones de los testigos, no habría comercio con los países donde no se ha estado ni con personas a las que no se conoce. Tal proposición, si fuese aceptada, trastornaría la sociedad. Bibliotheque Britannique, T. XXII, p. 271 (En francés en el original) (Nota del autor).

${ }^{19}$ Mer-man en inglés, dado que mermaid es sirena, hemos optado por traducir mer-man como su equivalente masculino.
} 
La existencia de esta criatura es cuestionada por $\operatorname{muchos}^{20}$, y no es para sorprenderse, porque muchos de los relatos que se han oído acerca de ello están mezclados con fábulas, y pueden ser tomados como cuentos vanos.

Historia de un sireno. Así es la historia de un sireno capturado por pescadores en Hordeland, cerca de Bergen, el cual, según ellos dicen, cantó una desagradable canción al rey Hiorlief. Jonas Ramus Véase la Historia de Noruega, p. $34^{21}$. Así es también el relato dado por Resenius, Relat. In vita Frederici II. Anno $1577^{22}$, de una sirena, que se llamaba a sí misma Isbrandt, y que mantuvo varias conversaciones con un paisano en Samsoe, en las cuales predijo el nacimiento de Cristián IV e hizo que el campesino predicara arrepentimiento a los cortesanos, que eran muy dados a la embriaguez. De acuerdo con A. Bussaeus (en su libro citado en Theatr. Europ. T. I anno 1619) ${ }^{23}$ los dos senadores, Ulf Rosensparre y Christian Holch, en su viaje de regreso a Noruega cogieron un sireno, pero se vieron obligados a llevarlo al agua de nuevo (186). Durante un tiempo yació sobre la cubierta, habló danés con ellos, y amenazó, si no se le daba la libertad, con que el barco naufragaría y perecería cada alma de la tripulación. Esto es tan vano como las otras historias. Cuando estas ficciones se mezclan con la historia del sireno, y cuando esta criatura es representada como profeta o como orador, cuando ellos dan a la sirena una melodiosa voz, y nos dicen que es una delicada cantante, uno no necesita sorprenderse de que muy pocas personas con sentido común den crédito a estos absurdos, o que incluso duden de la existencia de esta criatura.

\section{Sección III. Su existencia es posible, e incluso probable.}

La verdad. Sin embargo, aunque no tengamos motivo para creer todas estas fábulas, como la existencia de la criatura, podemos dar nuestro consentimiento con seguridad, ya que no es improbable ni imposible por la naturaleza de las cosas, y que no hay falta de

\footnotetext{
${ }^{20}$ Los viejos noruegos llamaron al hombre Hafstrambe, y a la mujer Maryge, de acuerdo con Andrew Bussaeus, en su Scriptum Monographum, impreso en Ol. Bang's Useful and Instructive Miscellanies, III, St. P. 531, confiando en un viejo manuscrito llamado Speculum Royale, extractado por Peter Clausen Undal, del cual he dado alguna noticia en el prefacio de la primera parte de esta obra, pero no sé si el mismo extracto existía en una copia que Bussaeus debe haber tenido, y mucho menos si el mismo trabajo fue visto detenidamente entre los manuscritos de Arnae Magni en la biblioteca de la universidad de Copenhague, de la que últimamente he sido (con sorpresa y placer) avisado por una carta del honorable B. Lundorph, consejero de estado (Nota del autor).

21 Jonas Danilsonn Ramus (1649-1718), clérigo noruego autor, entre otras obras, de una Norriges Kongers Historie (1719), que es a la que se refiere Pontoppidan.

22 Peder Hansen Resen (Petrus Resenius)(1625-1688), historiador y jurista danés, autor de Kong Frederik II's Kronnik (1680).

23 Andreas Bussaeus (1679-1735), historiador danés. En la Biblioteca Real de Dinamarca se conserva un manuscrito suyo sobre el tema, titulado Relation om en Hav-mand, som 1723 har ladet sig see i Ostersoen, til Jaegermester og Amtmand Gram, Paa nogle Steder rettet med Forfatterens egen Haand.
} 
confirmación de testigos creíbles, y que por ello no deben ser rechazados. Dadas ambas proposiciones, mostraré estar bien fundamentado. Pero antes de proceder, me aventuro a describir nuestro sireno y sirena noruegos, e igualmente sus jóvenes llamados Marmaete o Marmaele. Si se juzga acerca de este asunto (a priori) y se inquiere sobre si es probable, que encontremos en el Océano un pez o criatura, que se asemeje a la especie humana más que ninguna otra, ello no puede ser negado porque podemos responder afirmativamente, dado la analogía y semejanza que se ha observado entre varias especies de tierra y los animales marinos. Es bien conocido que hay caballos marinos, vacas marinas, lobos marinos, cerdos marinos, perros marinos, etc ${ }^{24}$, que guardan una cercana semejanza con los animales terrestres de estas especies, así que sería admitido y razonable, aunque algunos puedan hacer alguna objeción fundamentada en el amor propio y el respeto a nuestra propia especie, que es honrada con la imagen de Dios, que ha hecho al hombre señor de todas las criaturas, y que por consiguiente podemos suponer que tiene derecho a una forma tan noble y celestial de la que otras criaturas no deben participar, de acuerdo con las palabras del poeta.

Y aunque inclinados contemplen los demás vivientes la tierra,

Una boca sublime al hombre dio y el cielo ver

Le ordenó ${ }^{25}$.

Pero la fuerza de estos argumentos se esfuma cuando observamos la forma de los monos, especialmente la de los grandes babuinos de Africa (187), y mucho más cuando consideramos otra criatura africana, llamada Quoyas Morrov, de la cual Odoard Dapper, en su Descripción de Africa, p. $583^{26}$, proporciona la siguiente descripción:

"En los bosques del reino de Angola, o Dongo, encontramos un animal llamado Quoyas Morrow, esto es, el hombre del bosque, se encuentra también en Quoya, y en Bromi.

\footnotetext{
${ }^{24}$ Hasta el punto de que se hace verdadera la opinión del vulgo de que todo lo que nace en alguna parte de la naturaleza también se halla en el mar (En latín en el original), Plinio, Historia Natural, lib. IX, cap. 2. Esto es confirmado por nuestros pescadores, que no saben nada de la autoridad de Plinio, por su propia experiencia (Nota del autor). Si he de confesar la verdad, en tanto que historiador natural hasta ahora no he podido descubrir rasgo alguno, partiendo de principios científicos, por el que se pueda diferenciar al hombre del mono. Se dan, en efecto, en algunos lugares de la tierra monos menos velludos que el hombre, de cuerpo erguido, que caminan, igual que aquel, sobre dos pies, y que por el uso de las manos y de los pies recuerdan a la especie humana, de modo que se les podría hacer pasar absolutamente por cierta especie de hombres exóticos, aunque más toscos. El lenguaje, ciertamente, etc. Pero este es una cierta facultad o bien un resultado, no un rasgo característico. Carolus Linneo, en el prefacio de su Fauna de Suecia, p. 2. Carolus Linnaeus Flora svecica exbibens plantas per Regnum Sveciae crescente, p. 2(En latín en el original) (Nota del autor).

25 OVIDIO, Metamorfosis, I, 84-86. En latín en el original. Traducción de Ana Pérez Vega en Ovidio, Metamorfosis, Biblioteca Virtual Universal, 2003.

26 Olfert Dapper (1636-1689), médico y escritor holandés, que aunque nunca salió de su país publicaría una Naukeurige beschrijvinge der Afrikaensche Eylanden (1668) (Descripción de Africa), traducida al inglés en 1670.
} 
Se parece mucho a un hombre, de ahí que muchos crean que ha sido producido por la mezcla entre un hombre y un mono, o un mono y una mujer. Una criatura de esta especie fue hace algunos años traída a Holanda, y presentada a Federico Enrique, príncipe de Orange ${ }^{27}$. Era tan alto como un niño de tres años, y tan corpulento como uno de seis, estaba fuertemente construido, y cubierto por detrás con un pelaje negro. El semblante de este animal se parecía al de un hombre, la nariz era plana, las orejas como las humanas, tenía dos pechos protuberantes, un ombligo, y todas sus extremidades como las de la especie humana, tales codos, manos, piernas, y músculos de las piernas y tobillos. Con frecuencia andaba erguido, y podía coger un objeto pesado y arrojarlo. Cuando quería beber, ponía la mano en la parte inferior de una jarra, y con la otra agarraba la tapa y bebía, limpiando después sus labios. Cuando se recostaba para dormir, descansaba regularmente su cabeza sobre una almohada, y se cubría cuidadosamente con la ropa de cama, así que cualquier persona juraría que era un hombre durmiendo en el lugar. Se ha señalado que estos animales atacan y violan a las mujeres, y que algunas veces atacan a hombres armados. En conjunto, estos animales se parecen a los sátiros de los antiguos".

\section{Sección IV. De hecho existen, lo cual está probado sin duda, tanto por testimonios de noruegos y de extranjeros. Descripción de estos animales marinos.}

Meer-Minne. Si no otorgamos a nuestro Hastromber noruego el honorable nombre de sireno, podemos llamarlo muy bien mono marino, o el Sea-Quoyas Morrov, como el autor ya indicado dice, en la página 584, "En el mar de Angola son capturadas con frecuencia sirenas, que se parecen a la especie humana. Son cogidas en redes, y matadas por los negros, y se les oye chillar como a las mujeres. Los habitantes de esa costa comen su carne, a la que son muy aficionados, porque dicen que su sabor es muy parecido al cerdo. Las costillas de estos animales son consideradas un buen antihemorrágico, y de un cierto hueso en la cabeza, que separa el cerebro, se dice que es un poderoso remedio contra el mal de piedra" (188). Añadiré a todo ello un pasaje relativo a este ser, que puede ser encontrado bajo el artículo Meer-mann, p. 658, en el Universal Dictionary of Arts and Sciences, publicado por John Theodore Jablonsky ${ }^{28}$ : "Meer-man, Meer-weib, Meer-minne, esto es, hombre marino, mermaid, o sirena,

\footnotetext{
${ }^{27}$ Federico Enrique de Orange-Nassau (1584-1647), estatúder de las Provincias Unidas desde 1625 hasta su fallecimiento.

28 Johann Theodor Jablonski (1654-1731), lexicógrafo y educador alemán que también escribió bajo el nombre de Pierre Rondeau, y autor de Allgemeines Lexicon der Künste und Wissenschaften (Diccionario General de las Artes y las Ciencias), publicado en 1721.
} 
llamada por los indios Ambisiangulo, de otro modo Pesiengoni, y por los portugueses Pez mujer, es un pez encontrado en los mares y en algunos ríos en la parte meridional de Africa y la India, y en las islas Filipinas y Molucas, Brasil, Norteamérica, y Europa, en el mar del Norte. La lengua de este pez es de seis palmos, su cabeza es ovalada, y el rostro se asemeja al de un hombre. Tiene una frente alta, ojos pequeños, nariz chata, boca grande, pero sin barbilla ni orejas. Tiene dos brazos, que son cortos, pero sin articulaciones ni codos, con manos o patas, en cada una de las cuales hay cuatro dedos (que no son muy flexibles) conectados el uno al otro con una membrana, como el pie de un ganso. Su sexo se distingue por las partes de la generación. Las mujeres tienen pechos para amamantar su descendencia, así que la parte superior de su cuerpo se parece a la de la especie humana, y la parte inferior a la de un pez. Su piel es de color marrón grisáceo y, asado sobre una parrilla, es un plato muy gustoso para los indios. Gimotea un lamentable llanto cuando es sacado fuera del agua. Hay un hueso en la cabeza que divide el cerebro, que los portugueses reducen a polvo, y dicen que es de gran ayuda para el mal de piedra". Relatos de capturas de estos hombres marinos o sirenos en Europa son transmitidos por Wormius ${ }^{29}$, Guiccardino ${ }^{30}$, Mexia ${ }^{31}$, Seybold ${ }^{32}$, Erasmus ${ }^{33}$, Franciscus y otros".

Athanasius Kircher da la descripción del pez mujer, en su tercer libro De magnete P. VI. C. I. \&6, p. $675^{34}$. "Se captura en ciertas épocas del año en el mar de la India oriental, junto a las islas Visayas, a las que llaman "Islas de los Pictos", bajo dominio de los españoles, cierto pez antropomorfo, esto es, de forma enteramente humana, al que por ello denominan "pez mujer", mientras que los indígenas lo llaman "duyon". Tiene cabeza redonda, unida sin cuello al tronco; los filos de sus orejas, que también se denominan “orejillas", están revestidos con elegancia de una carne cartilaginosa, cuya parte interior, formada por amplísimas sinuosidades, recuerda una verdadera oreja humana; los ojos, adornados con sus propias pestañas, por su posición y su color no los juzgarías de pez, sino de hombre; la nariz es algo aberrante, no asoma por ninguna parte entre mejilla y mejilla pero está dividida por un ligero

29 Olaus Wormius (1588-1654), también conocido como Ole Worms, y propietario de una conocida wünderkammer cuyo contenido fue publicado en Museum wormianum, (1655).

${ }^{30}$ Francesco Guicciardini (1483-1540), historiador italiano cuya obra más conocida es la Storia d'Italia (15371540).

31 Pedro Mexía (1497-1551), autor español cuya Silva de Varia lección (1540) conocería un gran éxito editorial, siendo traducida al italiano, francés e inglés.

32 Johann Georg Seybold (1617-1686), filólogo alemán.

${ }_{33}$ Se trata, naturalmente, de Erasmo de Rotterdam. En el retrato que de él realizara Hans Holbein el Joven en 1523, y conservado en la National Gallery de Londres, hay representada en un capitel una sirena con dos colas. 34 Athanasius Kircher (1601-1680), jesuita y erudito alemán afincado en Roma, y autor de una amplísima producción. La obra aquí citada es Magnes sive de arte magnetica (1641), y la cita correcta es p. VI, cap. 2, s. 6 (p. 772). 
tabique; debajo de ella, en cambio, posee unos labios muy semejantes en tamaño y en aspecto a los nuestros; una hilera continua de dientes, no de sierra como los que se dan, en el género de los peces, sino planos y muy blancos; al pecho, cubierto por una piel blanca, algo más ancho por ambos lados en relación al cuerpo, le nacen unas mamas, pero no caídas como las de las mujeres, sino redondas como las de las vírgenes, llenas de una leche blanquísima; los brazos, no largos, sino anchos, adecuados para nadar, y no diferenciados en codos antebrazos, manos o dedos; en los miembros destinados a la procreación no hay ninguna diferencia con los seres humanos ni en uno ni en otro sexo; tras éstos la cola termina en pez"35.

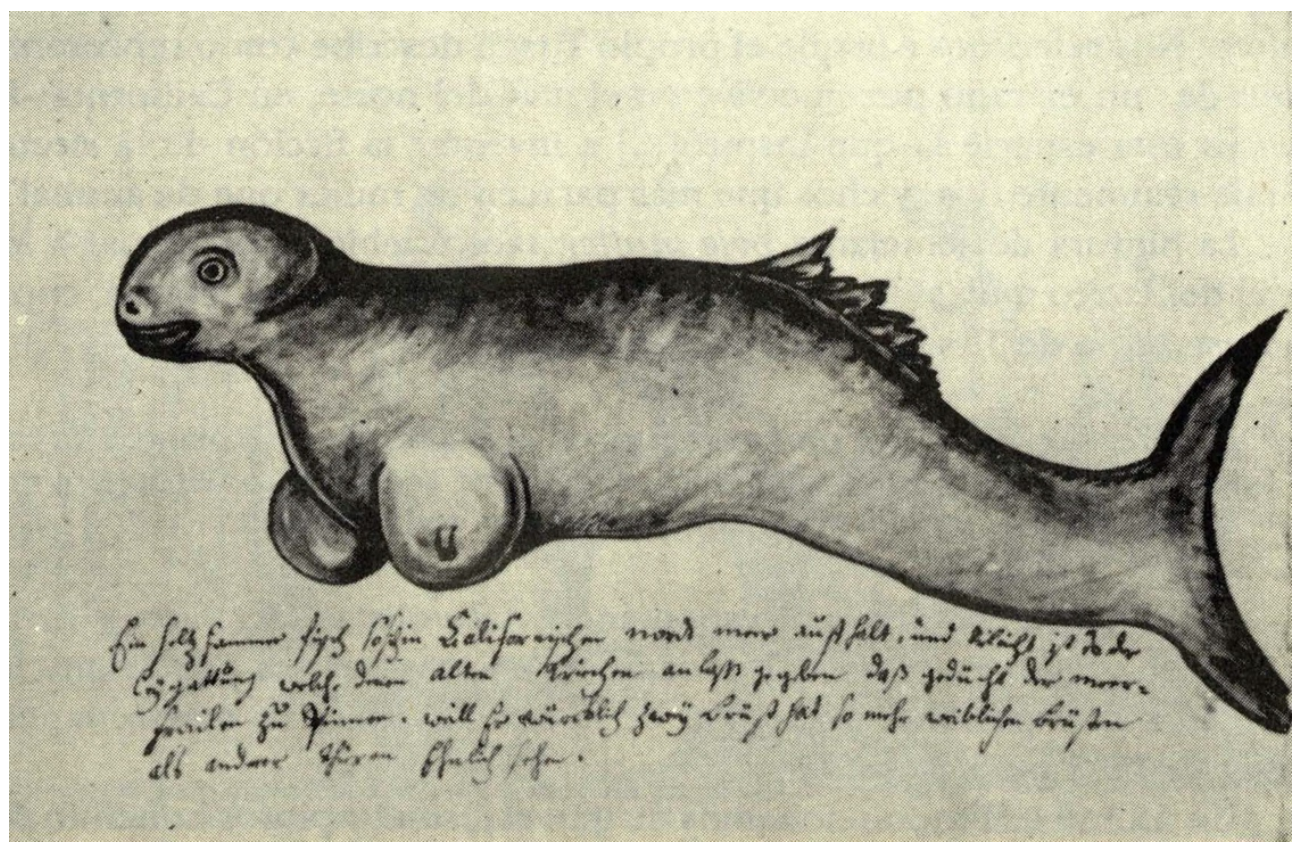

Imagen 2. Ignacio Tirsh (IHS), Imagen del pez mujer, siglo XVIII. Reproducido en Miguel LeónPortilla, La California mexicana. Ensayos acerca de su historia, primera reimpresión, México, UNAM, 2000, p. 207.

\section{Sección V. Más testimonios, y nueva descripción de ellos.}

Confirmación. Bajo estas autoridades puedo decir, que si la existencia del sireno europeo es puesta en cuestión, debe proceder enteramente de fabulosas historias mezcladas con la verdad ${ }^{36}$. Aquí, en la diócesis de Bergen, tanto como en el señorío de Norland, son varios centenares de personas de crédito y reputación que afirman, con la mayor seguridad, que han visto esta clase de criaturas, algunas veces a distancia, y otras bastante cerca de sus

\footnotetext{
${ }^{35}$ En latín en el original.

${ }^{36}$ En Everh. Happeliu's Mundus Mirabilis, se cuentan muchas historias, mezcladas con fábulas, concernientes al sireno, tomo III. Lib. I. cap. 18.
} 
embarcaciones, permaneciendo de pie, y formada hasta la mitad como una criatura humana, el resto no pudieron verlo. He hablado con muchas de estas personas, todos testigos oculares, sobre la existencia de esta criatura, y he tomado todas las precauciones posibles para examinar estrictamente esta materia. El resultado fue que todos coinciden en cada detalle de sus relatos, que responden a una descripción publicada hace poco por Jablonsky y Kircher, tanto como pudieron juzgar solamente por su vista a una pequeña distancia. Pero de aquellos que los han visto fueras del agua y tocado, no he sido capaz de encontrar más de una persona de crédito que pueda confirmar esto como verdadero. Como puedo con seguridad dar crédito a esta persona, a saber, el reverendo Mr. Peter Angel, que está todavía vivo, y administra la parroquia de Vand-Elvens Gield, en Sundmoer, relataré lo que me aseguró el último año, cuando yo estaba en mi viaje de visita pastoral. Dice que en el año 1719, cuando tenía veinte años de edad, junto con otros varios habitantes de Alstahoug en Norland, vio lo que denominó un sireno, yaciendo muerto en tierra cerca del mar, y que había sido arrojado por las olas, junto con varias focas y otros peces muertos. La longitud de esta criatura era mucho mayor de lo que haya sido mencionada por nadie anteriormente, a saber, más de tres brazas. Era de color gris oscuro, en la parte inferior era como un pez, y tenía una cola como la de una marsopa. La cara recordaba la de un hombre, con una boca, frente, ojos, etc. La nariz era chata, como si fuera aplastada (190) hasta la cara, en la que las fosas nasales eran muy visibles. El pecho no estaba lejos de la cabeza, los brazos parecían colgar de los lados, a los cuales se unían por una delgada piel membranosa. Las manos eran, en apariencia, como las patas de una foca. La parte trasera de esta criatura era muy grasa, y una gran porción de ella fue cortada, junto con el hígado, proporcionando una gran cantidad de aceite. Que esta criatura, que es considerada entre la clase de las ballenas, sea un pez de presa y viva entre las especies más pequeñas, puede ser concluida de lo que relata Mr. Luke Debes, en su Description of Feroe ${ }^{37}$. Sus palabras son, en la página 171, como siguen: "Fue vista en 1670, en Feroe, Westward of Qualboe Eide, por muchos de sus habitantes, y también por otros de diferentes partes de Suderoe, una sirena, cerca de la orilla. Permaneció allí durante dos horas y media, y estaba en el agua hasta el ombligo. Tenía largos pelos en su cabeza, que colgaban hasta la superficie del agua alrededor de ella. Sostuvo un pez, con la cabeza hacia abajo, en su mano derecha. Se dijo también que en el mismo año un pescador en Westerman-haven, en Stromoe, había, pescando al norte de las Feroe, visto una sirena".

${ }^{37}$ Lucas Jacobson Debes (1623-1675), sacerdote danés autor del primer libro sobre las Feroe, y del primer mapa detallado de Islandia. La obra a la que se refiere Pontoppidan es Faroa \& Faroa reserata, edición danesa 1673, inglesa 1676. 
Tormodus Torfaeus cuenta que varios sirenos, junto con otros monstruos, fueron vistos al mismo tiempo en la costa de Islandia, en su Hist. Norv. T. IV. L. VIII. P. 416, y así lo refiere en su Account of Greenland ${ }^{38}$. Siento no tener este trabajo a mano, porque sería curioso saber más sobre esta materia, pero en el lugar mencionado nos indica "Hemos visto muchas sirenas en un promontorio al sur de Islandia, llamado Surdness, llamado Hastrambe por los marineros (del que se puede leer en el capítulo XIII de nuestra Groenlandia), que se observan en Islandia, con el viento en sentido contrario" ${ }^{\text {"39. }}$.

"Se han visto Sirenas y otros muchos monstruos cerca de los promontorios del sur de Islandia, denominados Surdness, y, entre éstos, unos marineros a los que el viento arrastró de vuelta hacia Islandia avistaron al que llaman "Hafstrambe" (sobre el cual puede consultarse nuestro capítulo XIII, "Groenlandia")".

Que estas criaturas, siendo peces de presa, algunas veces se pelean con las focas, está confirmado por una relación que me enviaron, con varias otras, por el reverendo Mr. Hans Strom, en Borgen. Dice a tal efecto "Sucedió en Neroe en Numeladen, que allí fueron encontrados un sireno y una foca en una roca, ambos muertos, y cubiertos de sangre, de lo que se conjetura que se habían matado el uno al otro".

El reverendo Mr. Randulf, rector del lugar, se encontró con algún problema intentando conservar el sireno, porque los lugareños fueron antes que él y lo habían despedazado, con motivo de su grasa. Si entre esos sirenos, o como puedan ser llamados, monos marinos, hay alguna diferencia específica en forma o tamaño (191) (como he observado antes que los monos auténticos difieren de la criatura llamada Quoyas-Morrow, aunque en ambos hay similitudes con los humanos) no lo puedo decir con certeza. Sin embargo, pienso que la hay, y no sin alguna probabilidad. Considerando al menos su tamaño, difieren mucho en todas sus partes, de acuerdo con los pescadores, del bien conocido animal marino llamado Marmale, o Marmaete. Esto será descrito posteriormente, y puede ser considerado como un enano de estas especies. El arriba mencionado, en el pasaje copiado de Mr. Angel, con tres brazas de largo, puede, de la misma manera, ser considerado un gigante.

En 1624 un sireno, de 36 pies de largo, fue capturado en el Mar Adriático, pero de acuerdo con la Breviar. Histor. de Henry Seebald, el último mencionado era como un enano. Véase pag. 535. Por su forma, se ha dicho que algunos tienen una piel sobre su cabeza como la capucha de un monje, lo que quizás sirve para los mismos propósitos que una capucha

38 Thormodus Torfaeus (1636-1719), anticuario islandés y autor de Groenlandia Antiqua (1706) e Historia Rerum Norvegicarum (4 volúmenes, 1711).

${ }^{39}$ En latín en el original. 
delgada, como las que tienen algunas clases de focas en sus cabezas, de allí que sean llamadas Klap-mutzer, como ha sido observado en las descripciones de esas criaturas. Olao Magno habla, en el lib. XXI, cap. I., de varios monstruos en el mar del Norte $^{40}$, todos ellos parecidos a la especie humana, con una capucha de monje en la cabeza. Sus palabras son, "de forma humana con un capuchón" ${ }^{41}$. Añade que si alguno de los de esta especie es capturado, otros lanzan un aullido, se ponen en una violenta agitación, y obligan a los pescadores a dejar al prisionero en libertad. Pero este último relato es un mero romance, al cual este autor demasiado crédulo, como en otros tantos asuntos, ha dado demasiado crédito, sin suficiente base. De este sireno con capucha habla Rondelet ${ }^{42}$, así como Gesner de. Aquatilibus lib. IV. que no puedo omitir.

"Entre los monstruos marinos se encuentra también el que se capturó en Noruega en nuestro tiempo en el mar tempestuoso. Todos cuantos lo vieron le pusieron de inmediato el nombre de "monje". Parecía de rostro humano pero tosco y salvaje, de cabeza pulida y lisa. Cubría sus hombros una capucha como la de nuestros monjes. En lugar de brazos tenía dos largas alas. Su parte inferior terminaba en una larga cola. La intermedia era mucho más ancha, con forma de capote militar. Este dibujo me lo regaló la ilustrísima Margarita, reina de Navarra, etc. Ella había recibido este dibujo de un noble varón que le llevaba uno similar al emperador Carlos, que por entonces reinaba en España. Le aseguró a aquella reina que él mismo había visto capturar a este monstruo en Noruega tras haber sido arrojado a la orilla por las olas y las mareas tras enormes tempestades, e identificaba el lugar como "die Zundt", junto a la fortaleza de Ellepoch. Una pintura de este mismo monstruo que le había sido enviada a Roma desde la propia Noruega me la enseñó el médico Gisberto, la cual no difería mucho de la mía. De ahí que piense, por deciros mi opinión, que los pintores exageraron la realidad para que suscitara mayor admiración y, en definitiva, me inclino a creer que este monstruo recuerda la forma humana solo en la medida en que lo hace una parte de la cabeza de los rapes, porque detrás de la cabeza le salían por ambos lados dos apéndices equivalentes a los omóplatos humanos y movidos por unos músculos con forma de capucha de monje, tal como podemos verla entre nosotros, el segundo músculo, al poner en movimiento los omóplatos, esto es, al contraerlos y soltarlos, recuerda absolutamente la forma de la capucha de un monje. Además de esto, no creo que esté cubierto de escamas, sino de una piel dura,

\footnotetext{
40 Olaus Magnus (1490-1557), escritor sueco autor de la archiconocida Historia de Gentibus Septentrionalibus (1555).

${ }^{41}$ En latín en el original.

42 Es el pez monje que aparece en la obra del francés Guillaume Rondelet (1507-1566) Histoire entiere des poissons, Lyon, 1558, p. 361.
} 
rugosa, como una corteza, igual que decimos del león marino ${ }^{43}$ ".

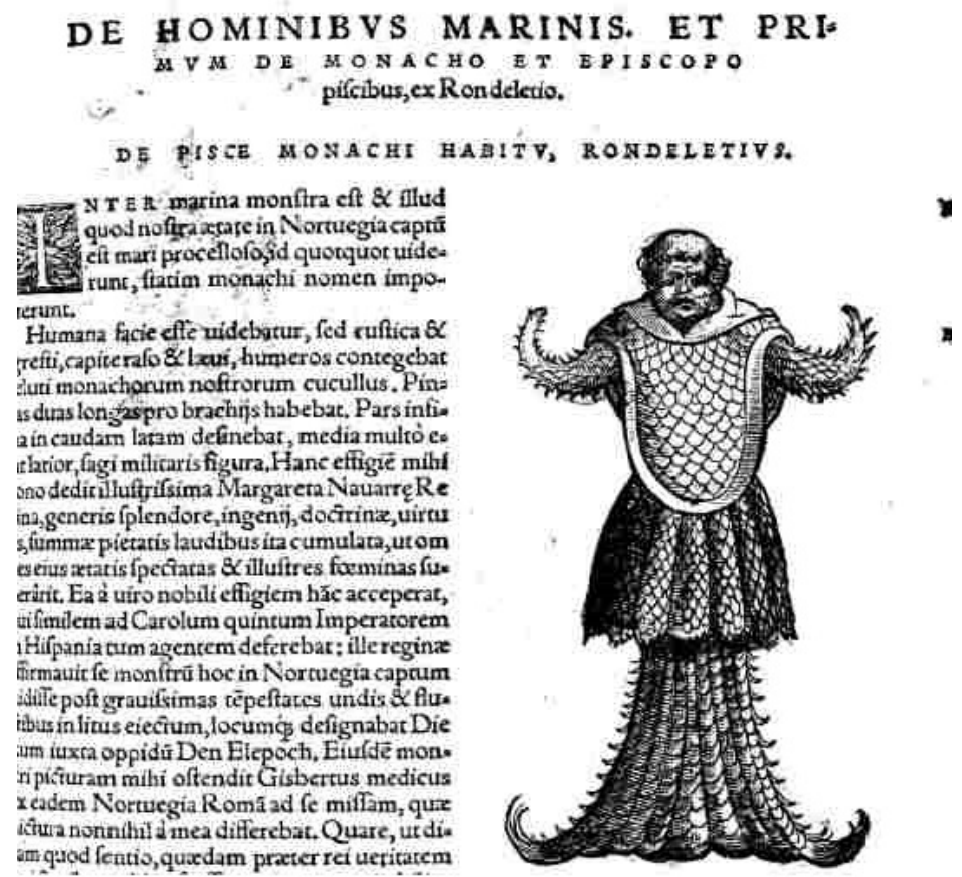

Imagen 3. El pez monje, en Konrad Gessner, Historiae animalium lib. IV. Piscium et aquatilitum animantium natura, Zurich, 1558, p. 519.

https://books.google.es/books?id=zfEN9BfeGxwC\&printsec $=$ frontcover\&dq=gesner + hi storiae + animalium\&hl $=$ es\&sa $=\mathrm{X} \& v e d=0$ ahUKEwj $70 \mathrm{Zu}-$

pvDeAhVJPBoKHaDwCm4Q6AEIOzAC\# ${ }_{\mathrm{v}}=$ onepage\&q=gesner $\% 20$ historiae $\% 20$ anima lium\& $\mathrm{f}=$ false

Como en este relato se confunde Noruega con el Sund y con Malmoe, a la que los holandeses llaman Elbow, concluyo que este extraño pez del que aquí se habla ha sido el mismo al que se refiere Arild Hvitfeld in vita Christ. III, ad ano $1550^{44}$. Dice que fue capturado en Oresund, y llevado a Copenhague, donde fue quemado por orden de su majestad, porque la cabeza parecía la de una criatura humana, con el pelo recortado, y cubierto con la capucha de un monje. Hay además una diferencia observada en las partes inferiores y la cola del sireno o sirena. Estos son representados en muchas de las pinturas de los pecados, al igual que otros peces, y con una cola plana y dividida, como la de las marsopas, de la que difiere por completo la imagen de una sirena que Thom. Barthol. nos da en su Historiar. Anatomicar. Centur. II. N. IX p. $188^{45}$, porque la extremidad inferior está allí representada con una protuberancia

\footnotetext{
${ }^{43}$ En latín en el original.

${ }_{44}$ Arild Hvitelfdt o Huitfeldt (1546-1609), historiador y funcionario danés, autor de Danmarks Riges Kronike (Crónica del Reino de Dinamarca, 8 vols, 1595-1603).

45 Thomas Bartholin (1616-1680), médico danés autor de Historiarum anatomicarum rariorum , 3 vols, 1654-1661.
} 
redonda, sin la menor referencia al pecado, ni cualquier otra cosa como la cola de un pez.

La anatomía de las manos de la sirena, a la que representa el autor, y que él tuvo en su posesión, junto con una costilla de esa criatura, son, sin ninguna duda, las mismas de las que da noticia Ol. Jacobaeus en su Mus. Reg. P. $15^{46}$, y donde no se cuestiona la existencia de esta criatura, al igual que el último escritor. Bartholine, en el lugar antes mencionado, señala el testimonio de varios escritores extranjeros, y concluye al respecto en la pág. 191 con estas palabras: "Tanta es la discrepancia entre los antiguos y los modernos sobre la forma de las Sirenas (193) que no es de extrañar algunos las tengan por ficciones. Nuestras manos se guían por los ojos y a las Sirenas las representamos como si las hubiéramos visto en realidad. Ni sus manos ni sus costados son falsos pues las imágenes que de ellos hemos elaborado están en consonancia con la verdad de la naturaleza" ${ }^{\prime 4}$.

Últimos casos. El último caso del que he oído haber sido visto un sireno, fue en Dinamarca, y éste está muy bien atestiguado, y merece ser señalado junto a los demás. Lo referiré tal como se encuentra en Ol. Bang. Collections, p. 528, tal como sigue: “Año 1723, el 20 de septiembre, el burgomaestre, A. Bussaeus, de Elsenor, había examinado, por orden de su majestad, a tres barqueros, habitantes de Elsenor, ante el consejero privado Frid. Von Gram. Sus nombres eran Peter Gunnersen, de 38 años, Nicholas Jensen, de 31, su hermano, y Jeppe Jenson Gissen, de 29. Estos hombres fueron interrogados acerca de un monstruo marino, que afirmaban haber visto unas semanas antes, y sus deposiciones fueron tomadas bajo sus respectivos juramentos, en orden a corroborar su testimonio.

Pareció que dos meses antes, los dichos barqueros estaban remolcando un barco recién llegado al Báltico, y que estaba a toda vela, a una considerable distancia de tierra, estando entre Hveen y Sedland, donde podían ver las torres de las iglesias de Landscrone. El tiempo calmo les indujo a recostarse un rato, y a la distancia de una milla inglesa, o un cuarto de milla noruega, observaron en el agua algo así como un cuerpo muerto, que enfilaba hacia ellos, así que pudieron ver cómo era. Cuando llegaron a siete u ocho brazas, apareció por primera vez, porque no se había movido, pero en ese instante se hundió y vino casi inmediatamente después al mismo lugar. Tras esto, sin sentir temor, se quedaron inmóviles, y entonces dejaron el barco flotando, para que pudieran examinar mejor al monstruo, el cual, ayudado por la corriente, se acercaba a ellos cada vez más. Volvió su cara, y miró fijamente a los hombres, dándoles una buena oportunidad de observarle estrechamente. Permaneció en

\footnotetext{
46 Oliger Jacobaeus (1650-1701), también conocido como Holger Jacobi, médico y naturalista danés autor de Museum regium, sive catalogus rerum, \&c. quee in basilica bibliotheca Christiani V. Hafnise asservantur (1696).

${ }^{47}$ En latín en el original.
} 
el mismo lugar durante medio cuarto de agua, y fue visto sobre el agua por encima del pecho, por último se mostraron temerosos de algún peligro, y empezaron a retirarse. El monstruo resopló sus mejillas, e hizo una especie de ruido rugiente, y entonces se sumergió bajo el agua, y no le vieron más.

En razón de su forma y aspecto, dijeron que parecía como un viejo, de fuertes miembros, y anchos hombros, pero no pudieron ver sus brazos. Su cabeza era pequeña en comparación con el cuerpo, y tenía el pelo rizado y corto (194), puesto que no llegaba a las orejas, sus ojos yacían profundamente en su cabeza, y tenía una cara delgada y magra, con una barba negra, que parecía haber sido recortada. Su piel era gruesa, y llena de pelo. Peter Gunnersen relató (lo que los demás no observaron) que este sireno era, en la parte inferior del cuerpo, como un pez. El mismo Peter Gunnersen igualmente depuso que veinte años antes cuando estaba en un bote cerca de Kulleor (el lugar donde había nacido) vio una sirena con pelo largo, y grandes pechos. Estos barqueros señalaron además que el tiempo estaba muy calmado durante ese día, y durante varios días siguientes.

Que este examen fue recogido de la forma más regular y exacta, atestigua, en Elsenor, ut supra

Andrew Bussaeus".

Mientras estoy escribiendo esto, el reverendo Mr. Hans Strom me informa que en Bergensund, en Sundmoer, también se ha visto este verano un sireno de la forma común, sin embargo, en todos estos relatos probablemente la fantasía ha exagerado un poco.

Marmaete. El antes mencionado Marmaele, o, como algunos le llaman, Marmaete, pertenece también a esta clase de la sirena, así que no lo consideraré su descendiente, pudiéndosele dar este nombre hasta que no sea examinado más atentamente. Esta criatura es a menudo capturada con ganchos, y es bien conocida por muchos pescadores. Son de diferentes tamaños, algunos de la grandeza de un niño de año y medio, otros de un año, y otros tan grandes como un niño de tres años, de este último tamaño fue capturado recientemente uno en Selloe-Sogn, la parte superior era como la de un niño, pero el resto como la de un pez, y quienes lo capturaron lo arrojaron directamente al agua. A veces los campesinos los llevan a sus casas, y, como ellos cuentan, les dan leche, que ellos beben. Nos dicen que estas criaturas giran sus ojos con extrañeza, como si estuvieran llenos de curiosidad o de sorpresa, por ver lo que no habían visto antes. Quienes se aventuran a llevarlos a casa, lo hacen con la esperanza de que les predigan alguna cosa, pero no los conservan más de veinte y cuatro horas, creyendo supersticiosamente que naufragarán en el agua, y los dejan en el mismo lugar donde los encontraron. 


\section{Sección VI. La gran serpiente marina, o la serpiente del océano, vista en la costa de Noruega, no es fabulosa.}

La gran serpiente marina, o serpiente del océano. El Soe Ormen, la serpiente marina, Serpens Marinus Magnus, denominada por algunos en este país el Aale-Tust, es un maravilloso y terrible monstruo marino, que merece ser referido por todos aquellos (195) curiosos de contemplar las extraordinarias obras del gran creador. Entre ellos el kraken, que voy a describir, es considerado como el más extraordinario en longitud. Pero aquí debo nuevamente, como lo hice con el sireno, dar primeramente noticia de las autoridades sobre la existencia real de esta criatura, antes de tratar de su naturaleza y sus propiedades. Esta criatura, particularmente en el mar del Norte, continuamente permanece en el fondo del mar, exceptuando los meses de julio y agosto, que es su época de desove, y entonces vienen a la superficie con el mar calmado, pero se sumergen en el agua de nuevo, tan pronto como el viento eleva la menor ola.

Si no fuera por esta regulación, así ordenada por el sabio Creador para la salvación de la humanidad, la realidad de la existencia de esta serpiente sería menos cuestionada en el presente, incluso aquí en Noruega, aunque nuestra costa es el único lugar en Europa visitado por esta terrible criatura. Esto hace que muchas personas, que son enemigas de la credulidad, manifiesten la mayor duda acerca de esto.

Muchos testigos no deben ser rechazados. Yo mismo he cuestionado su existencia, hasta que el recelo fue removido por muchas y suficientes evidencias de pescadores creíbles y experimentados, y marineros, en Noruega, de los cuales hay cientos que pueden testificar que la han visto cada año. Todas estas personas coinciden muy bien en la descripción general, y otros, que testimonian que sólo lo saben de oídas, o porque sus vecinos se lo han contado, relatan incluso los mismos particulares.

En toda mi averiguación sobre este asunto, apenas he hablado con ninguna persona inteligente, nacida en los señoríos de Noruega, que no sea capaz de dar una respuesta pertinente y sólidos testimonios de la existencia de este pez, y algunos de nuestros comerciantes del norte, que vienen aquí cada año con sus mercancías, piensan que es extraño que se les pregunte seriamente si hay alguna criatura parecida, por cuanto creen que es tan ridículo como que se les plantee si hay peces como la anguila o el bacalao.

El pasado invierno tuve por casualidad una conversación sobre esta cuestión con el capitán Lawrence de Ferry, ahora comandante en esta plaza, que dijo que había dudado mucho si había tal criatura, hasta que tuvo la oportunidad de convencerse por completo 
por una demostración ocular en el año 1746. Aunque yo no tenía nada material que objetar, estuvo dispuesto, como confirmación de lo que aseguraba, a traer ante los magistrados, a una sesión en la ciudad de Bergen, a dos marineros que estuvieron con él en un barco cuando disparó a uno de estos monstruos (196), y que vio a la serpiente, así como su sangre que coloreaba el agua. Lo que el susodicho depuso bajo juramento en el tribunal puede ser visto por el siguiente instrumento, cuyo original me fue enviado, y yo creo que se merece ser impreso tal cual. Dice lo siguiente:

Testimonio dado en las sesiones. "El abogado de su majestad en Bergen, Albert Christian Dafs, los registradores, Hans Christian Garner, John Clies, Oliver Simensen,. Oliver Briunchmand, George Konig por Conrad de Lange, Matthias Gram por Elias Peter Tucksen, Claus Natler por Didrick Haslop, Jochum Fogh por Henry Hiort, y George Wiers por Hans Christian Byssing, burgueses jurados, evidencian que en el año de Nuestro Señor de 1751, el día vigésimo segundo de febrero, en una sesión de justicia en esta ciudad de Bergen, compareció el procurador John Reutz, y presentó una carta que le había sido enviada ese día, del honorable Lawrence de Ferry, capitán de la armada, y primer piloto, fechada el día precedente, 21 de febrero, donde manifestaba su deseo de que el dicho procurador le proporcionara copias escritas de las respectivas deposiciones, testificadas bajo juramento, relatando el asunto antes mencionado y lo que había ocurrido, y el dicho procurador, ahora presente para tal propósito, suplica humildemente que los dos hombres llamados Nicholas Petersen Kopper, y Nicholas Nicholson Anglewigen, habitantes de esta ciudad, puedan ser admitidos para hacer juramento, cuyas deposiciones desea que puedan ser incluidas en el acta de esas sesiones. Esta fue en consecuencia leída a los dichos deponentes, y es como sigue.

Mr. John Reutz.

El último final de agosto, en el año de 1746, estaba en un viaje de regreso de Trondheim, en un día muy calmado y caluroso, teniendo en mente llegar a Molde, sucedió que cuando llegaba con mi barco a seis millas inglesas de la dicha Molde, estando en un lugar llamado Jule-Naefs, y leyendo un libro, oí una especie de murmullo entre los remeros, que eran ocho en número, y observé que el hombre al timón se mantenía alejado de la tierra. Tras esto pregunté qué pasaba, y fui informado de que había una serpiente marina ante nosotros. Entonces ordené al timonel que se dirigiera de nuevo hacia tierra, y que se acercara a dicha criatura, de la que había oído muchas historias. Aunque sus compañeros estaban recelosos, se vieron obligados a obedecer mis órdenes. En el entretanto esta serpiente marina pasó y 
nos obligó a (197) virar el barco, a fin de acercarnos a ella. Como la serpiente nadaba más rápido de lo que podíamos remar, cogí mi arma, que estaba cargada, y la disparé, e inmediatamente se sumergió bajo el agua. Remamos hacia el lugar donde se había hundido (que con la calma podía observarse fácilmente), y nos pusimos sobre los remos, pensando que volvería de nuevo a la superficie, sin embargo, no lo hizo. Cuando la serpiente se sumergió, el agua pareció densa y roja, quizás alguno de los disparos la hirió, ya que la distancia era muy pequeña. La cabeza de la serpiente, que sobresalió más de dos pies de la superficie del agua, parecía la de un caballo. Era de un color grisáceo, y la boca era bastante negra y muy larga. Tenía ojos negros, y una larga crin blanca que colgaba del cuello hasta la superficie del agua. Entre la cabeza y el cuello vimos siete u ocho repliegues de esta serpiente, los cuales eran muy delgados, y, tanto como pudimos conjeturar, había una braza de distancia entre cada repliegue. Relaté este asunto ante cierta compañía donde había presente una persona de distinción, que deseaba que le comunicara con detalle todo lo que sucedió, y por esta razón, dos de mis marineros, que estuvieron presentes en el mismo tiempo y lugar cuando vi al monstruo, llamados Nicholas Pedersen Kopper, y Nicholas Nicholson Anglewigen, comparecerán ante el tribunal para declarar bajo juramento la verdad de cada particular expuesto, y deseo el favor de una copia completa de la dicha descripción.

Permanezco, señor, como su obligado sirviente. Bergen. 21 febrero 1751.

L. de FERRY”.

Después de que los antes mencionados testigos prestaran su juramento, y con su dedo levantado de acuerdo a la ley, testificada y confirmada la antedicha carta de declaración, y cada particular expuesto, ser estrictamente la verdad. Una copia de dicho testimonio fue hecha para el dicho procurador Reutz, y garantizada por el registrador.

Esto fue trasladado a nuestra corte de justicia, lo que confirmamos con nuestra firma y sello”. Dado en Bergen, en el día y lugar antes dicho,
A.C. DASS. (L.S.)
H.C. GARTNER \&c. (L.S.). 


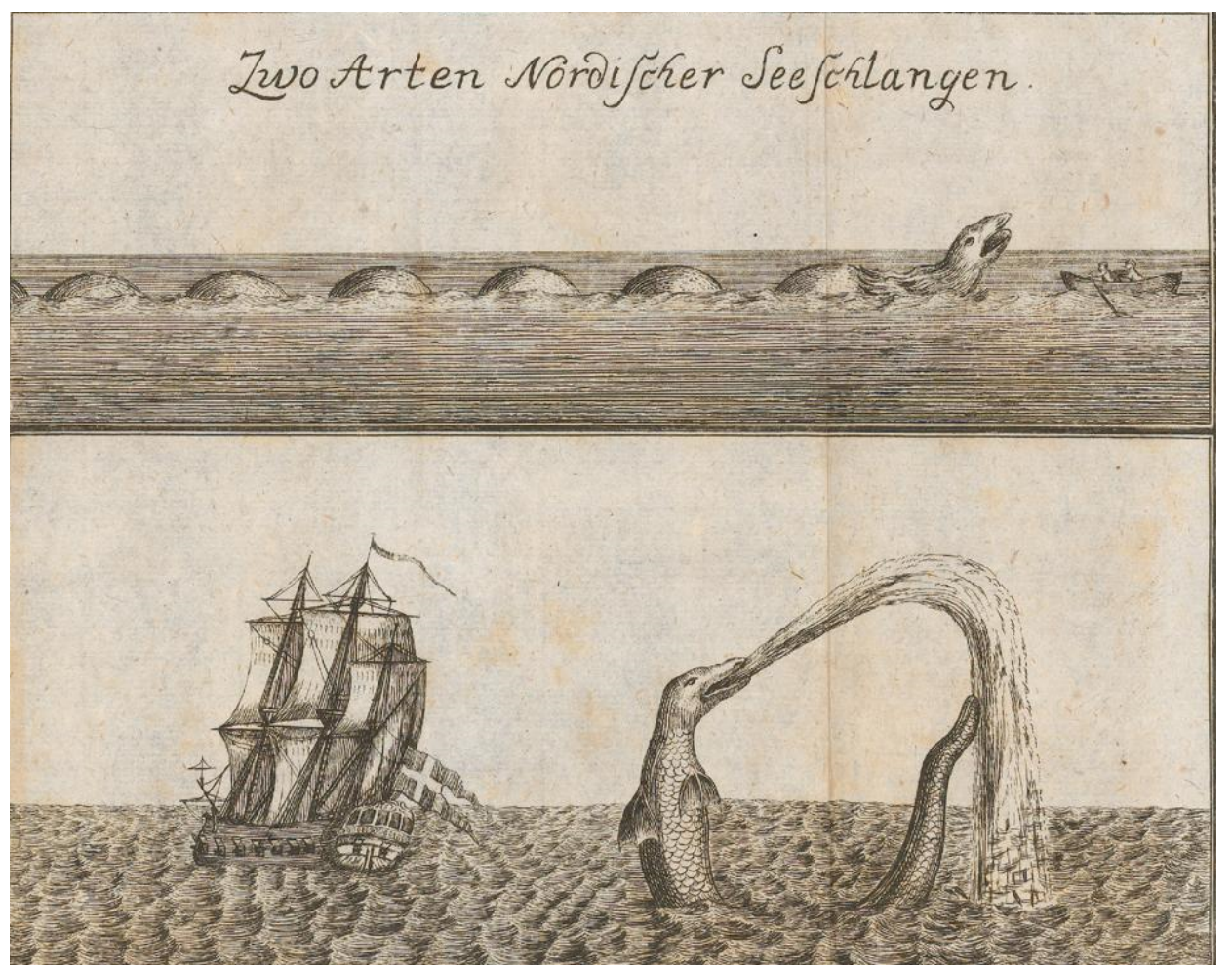

Imagen 4. La serpiente marina, en Erik Pontoppidan, Versuch einer natürlichen Historie von

Norwegen, Copenhague, 1754, p. 334. La ilustración de la edición inglesa es idéntica.

https://books.google.es/books?id=eQxYAAAAcAAJ\&printsec $=$ frontcover\&dq $=$ erik + po ntoppidan\&hl=es\&sa $=$ X\&ved=0ahUKEwjssoPsqPDeAhUStRoKHcUwATQQ6AEIbDA $\mathrm{J} \#_{\mathrm{v}}=$ onepage $\& \mathrm{q}=\mathrm{erik} \% 20$ pontoppidan $\& \mathrm{f}=$ false

\section{Sección VII. Su descripción.}

Forma. El gobernador Benstrum afirma que vio la misma criatura hace unos cuantos años, y que dibujó un esbozo de la serpiente marina (198), que deseo transmitir al público. Sin embargo, he insertado un borrador que fue facilitado por el clérigo antes mencionado, Mr. Hans Strom, el cual lo realizó cuidadosamente, bajo su propia supervisión. Este concuerda en cada particular con la descripción de este monstruo proporcionada por dos de sus vecinos en Herroe, nombrados Mess. Reutz y Tuchsen, del que habían sido testigos oculares. Puedo mencionar con el mismo propósito a muchas más personas de igual crédito y reputación. Otro dibujo, en que aparece con más detalle la forma de esta criatura, fue tomado del diario de la misión en Groenlandia del reverendo Mr. Egede, donde el relato aparece en la página $6^{48}$. "El 6 de julio de 1734, apareció una larga y espantosa serpiente

${ }^{48}$ Hans Egede (1686-1758), misionero luterano noruego denominado "el apóstol de Groelandia", y autor de Relation og Journal om der gronlandske Mission, manuscrito conservado en la Biblioteca Real de Dinamarca, así como de Det gamle Gronlands nye Perlustration (1729), traducido al inglés como A description of Greenland (1745). 
marina, que se alzó muy alto sobre el agua, tanto que su cabeza alcanzó el palo mayor. Tenía un largo hocico afilado, y levantaba un surtidor de agua como una ballena, y tenía patas muy anchas. El cuerpo parecía estar cubierto de escamas, y la piel era desigual y arrugada, y la parte inferior estaba formada como la de una serpiente.

Después de algún tiempo la criatura se sumergió hacia atrás en el agua, y entonces volvió su cola sobre la superficie con toda la longitud del barco desde su cabeza ${ }^{49}$. La tarde siguiente tuvimos muy mal tiempo”. Hasta aquí Mr. Egede. El dibujo anexo me da la mayor razón para concluir (lo que por otros testimonios he juzgado probable) que hay serpientes marinas, al igual que otros peces, de diferentes especies. Lo que Mr. Egede vio, y probablemente todos los que navegaban con él, tenía bajo su cuerpo dos faldillas, o quizás dos finas aletas, la cabeza era larga, y el cuerpo era más grueso ${ }^{50}$, pero mucho más corto que el de las serpientes marinas de las que he tenido relatos más consistentes. Aunque uno no puede tener una oportunidad de tomar las dimensiones exactas de esta criatura, todos los que la han visto son unánimes en afirmar que, tan lejos como pueden juzgar a distancia, parecen tener la longitud de un cable, es decir, cien brazas o 600 pies ingleses ${ }^{51}$, que permanece en la superficie del (199) agua (cuando está muy calmada) con muchos repliegues, y que se alinean con la cabeza, algunas pequeñas partes de la espalda son vistas sobre la superficie del agua cuando se mueve o se dobla. A distancia parecen como muchos barriles o pipas flotando en línea, con una considerable distancia entre ellos. Mr. Tuchsen de Herroe, a quien he mencionado arriba, es la única persona, de los muchos correspondientes que tengo, que me informa que ha observando la diferencia entre el cuerpo y la cola de esta criatura tanto como su espesor.

Parece que esta criatura, como el Eeel o la serpiente terrestre, disminuye gradualmente hasta la punta, pero el cuerpo, que parece ser tan grueso como el de dos barriles, permanece extraordinariamente pequeño justamente hasta donde comienza la cola. La cabeza en todas

\footnotetext{
${ }^{49}$ Recuerdo haber visto esta serpiente marina representada en una gran pintura en la casa de Mr. Jacob Severin, que había estado a cargo de expediciones a Groenlandia por orden de su majestad, y compuso un verso latino sobre ello, el propósito del cual era, tanto como puedo recordar, que miró con desdén al dragón infernal, que parece asustar a todos los que vienen con el deseo de ilustrar y convertir a los paganos de Groenlandia (Nota del autor).

${ }^{50}$ En New Survey of Old Greenland, pag. 48, el anteriormente mencionado Mr. Egede habla del mismo monstruo, con estos añadidos, que el cuerpo era tan grueso y grande en circunferencia como el barco en que navegaba. Mr. Bing, uno de los misioneros, que tomó un dibujo de él, informó a su cuñado, Mr. Sylow, ministro de Houghs en esta diócesis, que los ojos de esta criatura parecían rojos, y como fuego ardiente, todo esto hace que no parezca ser la serpiente marina común (Nota del autor).

${ }^{51}$ Fue probablemente, del aspecto de esta criatura, por lo que el valiente rey Oluf Trygvinsen llamó a su principal barco de guerra Ormen Large, esto es, Larga serpiente. Este extraordinario barco llevaba mil hombres armados, los cuales, con sus escudos dorados colgando sobre cada lado del navío, dieron a esta inanimada serpiente marina un aspecto no inferior al de la viviente (Nota del autor).
} 
las especies tiene una frente alta y ancha, pero en forma de un hocico puntiagudo, aunque en otras es plano, como el de una vaca o un caballo, con largas fosas nasales, y varios pelos rígidos colgando de cada lado como bigotes.

Se supone que la serpiente marina tiene un olfato muy agudo, lo que se puede concluir porque se ha observado que huyen del olor del aceite de castor. Considerando esto, quienes van a Stor-Eggen a pescar en verano, siempre se abastecen con estos animales. Añaden que los ojos de esta criatura son muy grandes, y de color azul, y parecen como un par de platos de peltre. El animal es de color marrón oscuro, pero manchado y abigarrado de rayas o puntos luminosos, que brillan como el caparazón de una tortuga. Es de un tono más oscuro bajo la boca y los ojos que en otras partes, y se parece en esa parte en buena medida a esos caballos a los que llamamos Moors-heads.

No encuentro en ninguno de mis correspondientes que lancen el agua por sus fosas nasales como la ballena, sólo en un testimonio relatado por Mr. Egede, mencionado arriba, pero cuando se aproxima, pone el agua en una gran agitación, y hace que corra la corriente como un remolino. Las de nuestras costas difieren mucho de las serpientes marinas de Groenlandia, en relación a su piel, que es lisa como el vidrio, y que no tiene la menor arruga, pero sobre el cuello hay una especie de crin, que parece como un montón de algas marinas, colgando fuera del agua. Algunos dicen que mudan anualmente la piel como la serpiente terrestre, y se afirma que hace unos pocos años fue vista en Kopperwiig una cubierta para una mesa hecha de la piel de una de estas serpientes. Esto aumentó mi (200) curiosidad por saber la verdad, y consecuentemente escribí para información propia, solicitando el favor de una prueba de ello, por medio de una muestra, pero parece que no hay tal cosa, o al menos no en aquel tiempo. Además, un hombre que vino de aquel lugar me dijo que él nunca había oído nada de ello. Esta persona sin embargo me informó que en el año 1720 una serpiente marina había estado toda una semana en un arroyo cerca de aquel lugar, y que llegó allí arriba a través de un estrecho canal de siete a ocho pies de ancho, pero se fue después de permanecer allí durante toda una semana, como se ha mencionado arriba, dejando atrás una piel, que el hombre, cuyo nombre es Thorlack Thorlacksen, declaró ver y sostener. Esta capa de piel permanece en el fondo del arroyo, y, por lo tanto, nadie pudo decir cuán larga era. Parece que el arroyo y el canal tienen varias brazas de profundidad, y se extiende durante un largo tramo, pero el otro extremo del mismo ha sido cegado por la marea, que permanece durante mucho tiempo como para que alguien lo pueda examinar. Dijo que no la había visto adecuada para cubrir una mesa, a menos que haya sido apropiadamente revestida, o preparada de alguna forma para tal propósito, porque no era tan dura ni compacta como el cuero, sino 
más bien de una consistencia suave y viscosa, como el del manatí antes descrito. Incluso se dice que el mismo cuerpo es de la idéntica naturaleza, tal como he sido informado por aquellos que por accidente una vez capturaron un ejemplar joven, y lo dejaron yacer sobre la cubierta del barco. Murió instantáneamente, aunque nadie se arriesgó a acercarse, y se vieron obligados a arrojarlo, por el insoportable hedor provocado por el viscoso limo en el que se disolvió por la acción del viento ${ }^{52}$. Parece que el viento es muy destructivo para esta criatura, como ha sido observado anteriormente, que nunca es vista sobre la superficie del agua, salvo con la mayor calma, y que al menor signo de viento se sumerge de nuevo. Una de estas serpientes marinas fue vista en Amunds Vaagen, en Nordfiord, hace varios años. Llegó a las rocas, probablemente desde alta mar, y murió allí. Se observó que el cuerpo provocó un hedor intolerable durante largo tiempo (201) y que lo dicho también sucedió en la isla de Karmen y en varios otros lugares. Deseo que en alguna oportunidad alguien haya examinado la criatura cuidadosamente, para ver si tiene una fuerte columna vertebral, que parece necesaria para soportar tal longitud.

La especie de tiburón, que es también de clase cartilaginosa, y sin otros huesos, aunque lo tiene en la espalda, si bien muy fino, incluso en las mayores especies, que a menudo tienen veinte pies de longitud. Las serpientes marinas parecen ser, como el tiburón, eel, o la ballena, vivíparas. Parece que se pelean con sus compañeros en ciertas épocas del año con la intención, como se ha dicho, de aparearse. Por este motivo se ha supuesto que siguen a los barcos y botes en estas épocas, que probablemente se parezcan a criaturas de su misma especie. Si esto, como he tomado de los relatos de nuestros marineros, es verdad, puedo concluir que están equivocados quienes suponen que la serpiente marina no crían en el mar, sino en tierra, y que viven en las rocas y bosques, hasta que no pueden ocultarse, y que entonces se dirigen a los ríos con la intención de ir al mar. Hay algunos que pretenden haber visto todo esto.

En el capítulo de las serpientes terrestres e insectos he observado que una transición repentina del agua dulce a salada parece muy improbable. Sin embargo, no desconfiaré por completo de lo que se cuenta de las serpientes marinas vistas en los lagos,

\footnotetext{
52 Tenemos el mismo relato del padre Labat, de una pequeña serpiente marina, de cuatro pies de largo, tan gruesa como el brazo de un hombre. Sus palabras son "La atamos al mástil después de haberla aturdido para ver qué aspecto tendría al día siguiente. Sabíamos cuán grande era nuestra felicidad por no haber tocado ese pez, que sin duda nos habría emponzoñado. Porque nos encontramos por la mañana que se había disuelto por completo en un agua verdosa y apestosa, que se había desparramado por el puente, sin que quedara cosa alguna más que la piel, que nos había parecido bastante firme y bastante buena. Concluimos que este pez estaba emponzoñado por accidente, o que por su naturaleza no era más que un compuesto de veneno. Yo creo que era alguna víbora marina. He hablado con algunos pescadores y otras gentes de mar, sin haber jamás esclarecido lo que deseaba saber sobre lo tocante a este pez. Nouveaux Voyages aux Isles Françoises de l'Amerique tom. V. cap. XIV. P. 335 (en francés en el original) (Nota del autor).
} 
algunos de los cuales, como en Sundfiord y en Uland, son famosos por estas criaturas, tanto que los habitantes de las tierras adyacentes no se atreven ni aventuran a cruzarlos en un bote.

\section{Sección VIII. E1 peligro de aproximarse a ella.}

Vuelvo nuevamente a la serpiente marina, así llamada propiamente, o la serpiente del Océano, y particularmente a la pregunta más interesante concerniente a ella, que es si hacen algún daño a la humanidad, y en qué manera pueden herir a la especie humana. Arndt. Bernsen, en su Account of the Fertility of Denmark and Norway, p. 308, afirma que lo hacen, y dice, que la serpiente marina, al igual que el Trold-whale, a menudo hunde tanto hombres como embarcaciones. No he oído ningún relato de tales accidentes por aquí, lo que podría aceptarse, pero los comerciantes del norte me informan de lo que con frecuencia ha sucedido con ellos, a saber, que la serpiente marina se ha levantado y se ha arrojado sobre un bote, y por su peso lo ha hundido al fondo. Uno de los dichos comerciantes del norte, que dice haber estado bastante cerca (202) de estas serpientes marinas (vivas) como para sentir su suave piel, me informa que algunas veces alzan sus horrendas cabezas, y sacan a un hombre del bote, sin dañar a los restantes, pero no afirmaré esto como cierto, porque no es cierto que sean peces de presa. Sin embargo, su enemistad hacia la humanidad no puede ser más determinada que la de la serpiente terrestre, según las palabras del profeta Amós cap. IX v. 3. "si se ocultan a mis ojos en el fondo del mar, allí mismo ordenaré a la Serpiente que los muerda" ${ }^{25}$.

Se ha dicho que a veces se enroscan en un amplio círculo alrededor de un barco, así que los hombres se encuentran rodeados por todas partes. Esta serpiente, como he observado anteriormente, generalmente aparece en las aguas plegada o enrollada, y los pescadores, siguiendo una costumbre conocida en ese caso, nunca reman hacia lugares abiertos, o aquellos sitios donde el cuerpo no es visto, pero está sumergido bajo el agua, porque si lo hacen, la serpiente inmediatamente se alzaría, y zozobraría las barcas. Por el contrario, reman hacia el lugar más alto que sea visible, lo que hace que la serpiente inmediatamente se sumerja, y entonces se liberan de sus miedos. Este es su método cuando no pueden evitarla, pues cuando ven una de estas criaturas a distancia, reman con todas sus fuerzas (lo que a veces daña su salud) hacia la orilla o alguna cala donde no pueda seguirles.

Cuando están lejos de tierra intentar alejarse de ella será en vano, porque estas criaturas se deslizan a través del agua como una flecha fuera del arco, buscando

${ }^{53}$ En latín en el original. Traducción española de la Biblia de Jerusalén. 
constantemente los lugares más fríos ${ }^{54}$. En este caso ponen en ejecución el siguiente método, tumban sus remos, y le arrojan cualquier cosa que tengan a mano. Porque si una cesta, o cualquier otra cosa ligera las toca, generalmente se sumergen bajo el agua, o siguen otro camino. Recientemente nuestros pescadores han encontrado el modo, en los cálidos meses de verano, de proveerse con aceite de castor, que siempre llevan consigo cuando se adentran en el mar. Lo guardan en un agujero en la proa, y si en cualquier momento están temerosos de encontrarse con la serpiente marina, arrojan un poco al agua, porque por experiencia saben con certeza que siempre evita esta droga. Luke Debes nos cuenta, en su Faeroa referata, pag, 167, que en ese país también lo usan con el mismo éxito, como la mejor defensa contra el Trold Whale, un pez que igualmente zozobra las embarcaciones, pero que tiene una gran aversión al aceite de castor y a las virutas de madera de enebro. Estos (203) se la arrojan por lo tanto cuando están en peligro. El autor ya citado también dice, que varios experimentos confirman este singular fenómeno, que si un hombre tiene aceite de castor sobre él cuando está en el agua, se hunde instantáneamente en el fondo como una piedra, aunque sea bueno como nadador. Sobre la verdad de ello señala el testimonio de Thom. Bartholin. In Centur. II. Histor. Anatom. Hist. 17, p. 201.

Un eminente boticario de aquí me ha informado que en lugar del aceite de castor, nuestros pescadores se proveen de assa foetida ${ }^{55}$, como medio de defensa contra estos dañinos animales marinos, porque como tiene un fuerte olor, tiene el mismo efecto sobre las serpientes marinas, además el assa foetida tiene un precio más bajo que el castor.

En las remotas partes de Noruega, de acuerdo con algunos relatos, las personas han sido emponzoñadas con los excrementos de la serpiente marina, que a menudo son vistos, especialmente en Norland, en los meses de verano, flotando en el agua como limo. Suponen nuestros pescadores que esta materia viscosa es algo vomitado por ellos, o quizás su esperma, o algún otro humor. Si un pescador encuentra esta sustancia cerca de su red, e inadvertidamente permite que toque su mano, le ocasionará una dolorosa inflamación e hinchazón, que a menudo se ha mostrado tan peligrosa que ha requerido la amputación del miembro.

Mr. Peter Dafs, en su Description of Norland, es de la opinión que esta serpiente marina puede ser llamada el Leviatán, o el Dragón del océano. Daré al lector algunos versos que él ha publicado sobre esta materia ${ }^{56}(204)$.

\footnotetext{
${ }^{54}$ Generalmente viran con sus botes, así que cuando la serpiente les persigue, debe mirar hacia el sol, cuya vista no soporta (Nota del autor).

${ }^{55}$ Ferula assafoetida, conocida en español como "estiércol del diablo", y que tiene un olor nauseabundo.

56 Prescindimos de proporcionar los versos en danés.
} 
La gran serpiente es el sujeto de mis versos

Porque mis ojos nunca la han visto todavía

Ni desearán tan horrenda visión

Aunque muchos relatos de hombres de verdad incuestionable

Cuyas palabras firmemente creo

La muestran como un monstruo sumamente horrible.

Cuando Julio entra en su estado principesco

Y el sol retorna de su aéreo curso

Entonces este espantoso monstruo primero aparece

Se ha dicho que tal es la perniciosa naturaleza

De esta horrible serpiente, que cada barco que ve

Primero lo persigue, y entonces intenta hundirlo.

Inmenso es su tamaño, enorme es su volumen

El cual por la experiencia, puede ser plenamente mostrado

Por aquellos que han contemplado este horrendo monstruo

Cuando reposa en el mar, estirado en su longitud

El parece como cien cargas, tan vasto su tamaño.

Creo que él parece otro Behemoth

O Leviatán, que desprecia

Todas las armas, como espadas, o cañones, o relucientes lanzas,

Porque el hierro es para él como paja o lino

Y el cobre como ramas que se doblan o se rompen

Pues así es descrito en la Sagrada Escritura (205).

\section{Sección IX. Si esta criatura puede ser considerada como el gran Leviatán.}

Si puede ser el Leviatán en vez de la ballena. He anotado estos versos, como una muestra de la existencia y de las propiedades de esta extraordinaria criatura. La suposición de que la serpiente marina responde a la descripción del Leviatán mejor que otro animal ya conocido, y puede ser entendido como el Leviatán, o la serpiente huidiza, Isaías XXVII. 1. que matará al dragón que hay en el mar, o que pueda ser la gran serpiente mencionada en Job XXVI. 13, no es sin algún fundamento. Que sea la serpiente perforante, o la serpiente árbol, Serpens vectis, según algunos autores, no es improbable, porque a menudo reposan tendidas 
en una ensenada, como un árbol, para bloquear el camino. Si Bochart ${ }^{57}$ tuviera algún conocimiento de esta criatura, que es muy poco conocida salvo en el norte, probablemente no hubiera tomado a la ballena por el Leviatán. "A la ballena los hebreos la llaman con los mismos nombres con los que se refieren, en efecto, al dragón Tanis y a Leviatán, bien por el parecido de su forma, a causa de su tamaño o bien porque la ballena sobresale entre los animales acuáticos tanto como entre los reptiles destacan por sus atributos los dragones"58. Hierozoic. Lib. I. cap. VI. P. 45. La similitud de la forma, que los escritores señalan como una mezcla de la ballena y el dragón, es lo que no puedo encontrar, ni tampoco puedo averiguar cómo este autor (al cual por lo demás estimo como uno de los más sabios que el mundo haya producido) viene a decir, en el mismo lugar, pag. 50, "muchos creen que a la "ballena" se la llama "serpiente travesaño" (Isaías 27.1) ${ }^{59}$, porque llega, a manera de un travesaño, de un extremo al otro del mar" ${ }^{60}$. Esto no concuerda con la ballena, que usualmente tiene 50, $70 \mathrm{o}$ más de 80 pies de longitud ${ }^{61}$, al menos no tanto como la serpiente de mar. La longitud de esta criatura, como he observado arriba, de acuerdo con nuestros pescadores que la han visto, es igual a la de un cable, esto es, 600 pies. Estas serpientes, como otras criaturas, pueden no ser exactamente de un mismo tamaño, pero algunas pueden ser el doble de largas que otras de su especie, tal como se observa en las serpientes terrestres, que difieren mucho en tamaño. He sido informado por algunos de nuestros marineros que un cable no sería lo suficientemente largo como para medir la longitud de alguna de ellas, cuando son observadas a todo lo largo en la superficie del agua. Dicen que se doblan o se repliegan algunas veces (206), tan lejos como un hombre puede ver. Confieso, si esto es verdad, que debemos suponer con mayor probabilidad que no es una serpiente, sino dos o más de estas criaturas reposando alineadas, lo que explica este fenómeno. Esto puede suceder porque se siguen unas a otras, especialmente en la época del año en que desovan, o se aparean. En esta estación también

\footnotetext{
${ }^{57}$ Samuel Bochart (1599-1667), erudito y ministro de la Iglesia calvinista francesa, autor de Hierozoicon (1663), donde historia todos los animales citados en la Biblia.

${ }^{58}$ En latín en el original.

${ }^{59}$ La locución latina "serpentem vectem” es de difícil interpretación. Vid. FLEMMING, John V.: “The Flight of Geryon”, en DUT'TON, M. L.; TERRELL GAY, P. (eds.): One Lord, One Faith, One Baptism. Studies in Christian Ecclesiality and Ecumenism in Honor of J. Robert Wright, Grand Rapids (Michigan)/Cambridge (UK), 2006, pp. 6898, (p. 90). Felipe Scio en La Biblia Vulgata latina traducida en español (tomo VI, Valencia, 1793) lo traduce como serpiente rolliza. La cuestión radica en que del verbo hebreo barach, huir, deriva la forma bäriyach, la que consta en el texto. Los LXX lo han interpretado como feugonta, pero san Jerónimo lo toma como la barra que pasa o atraviesa (=que huye por) las tablas para asegurar una construcción.

${ }^{60}$ En latín en el original.

${ }^{61}$ Bochart en el mismo lugar niega las palpables falsedades del Talmud acerca del tamaño de la serpiente etc. "Los hebreos, con frecuencia mendaces, mienten mucho y abundantemente en esta cuestión. Entre ellos los más moderados atribuyen a las ballenas una longitud de quinientos estadios, esto es, más de sesenta millas. En el Tratatus Talmudicus Bava Bathra, fol. 73, col. 2. Una nave tardó tres días en navegar por el dorso de una ballena desde uno a otro brazo" (En latín en el original) (Nota del autor).
} 
pueden ser inducidas a seguir a los barcos, como he mencionado antes. Debo observar además que lo que la palabra de Dios dice, en el lugar citado del Leviatán, verbigracia, que es tanto una serpiente doblada y una serpiente estirada, pronto doblada en curva, pronto estirada en línea, concuerda perfectamente con esta serpiente marina, de acuerdo con lo que ya se ha dicho ${ }^{62}$. Puede no ser superfluo anotar aquí las palabras de Mr. J. Ramus, en su Description of Norway, pag. 43, que es como sigue "Año 1687, una gran serpiente marina fue vista por muchas personas en Dramsfiorden, y en una ocasión por once personas juntas. Estaba el tiempo muy calmado, y tan pronto como el sol apareció, y el viento sopló un poco, se disparó como un cable enroscado, que repentinamente es arrojado por los marineros, y observaron que en su extensión había muchos repliegues". Olao Magno, en su Histor. septentrion. Lib. XXI c. 24, habla de una serpiente marina noruega de 80 metros de largo, pero tan delgada como el brazo de un niño. "Hay en las costas noruegas serpientes de color gris, de 40 codos de longitud, y que tienen el espesor de escasamente el brazo de un niño" ${ }^{\circ 3}$. Esta criatura, dice, fue tan dañada por los cangrejos posados sobre ella, que se retorcía sobre sí misma en cientos de formas. Nunca he oído nada de esta suerte de otra persona, y difícilmente creería al buen Olao, si no dijera que afirmaba esto de su propia experiencia. "Vi más a menudo esta serpiente, de cuyo contacto, según las informaciones de los marineros, se abstienen" ${ }^{\text {"64 }}$ La desproporción entre un espesor del brazo de un niño y una longitud de 80 pies me hace creer que debe ser un error de imprenta, por cuanto xl. quizás sería xi. ells, o 22 pies, una longitud más proporcionada para su anchura. De otra serpiente marina el mismo autor escribe posteriormente, cap. XXVII. Pero mezcla la verdad y la fábula juntas, de acuerdo con la relación de otros, aunque esto era excusable en esa época oscura (207) en la que el autor escribió. A pesar de todo, en esta presente era más ilustrada le estamos muy agradecidos, por su afán y por sus juiciosas observaciones. La suma de lo que relata en ese lugar es esto: "Aquellos que visitan las costas de Noruega nos hablan de un fenómeno muy extraño, a saber, que hay en estas aguas una serpiente de 200 pies de largo, y 20 pies de circunferencia, que vive en los huecos de las rocas, y bajo los acantilados, cerca de Bergen (aunque en esto yerra), y sale en las noches de luna llena para devorar terneros, ovejas, y

\footnotetext{
62 Si uno investiga cuantos pliegues pueden ser contados en una serpiente marina, la respuesta es que el número no es siempre el mismo, que depende de los varios tamaños de ella, veinte y cinco es el mayor número que he atestiguado. Adam Olearius, en su Gottorf Musaeum, pag. 17, escribe de esto "Una persona de distinción de Suecia, relató aquí en Gottorf, que él había oído al burgomaestre de Malmo, un hombre muy digno, decir que una vez estaba de pie en la cima de una alta colina hacia el mar del Norte, y él vio en el agua, que estaba muy calmada, una serpiente, que pareció a esa distancia ser tan gruesa como una pipa de vino, y tenía 25 pliegues. Esta clase de serpientes solamente aparecen algunas veces en agua calma" (Nota del autor).

${ }^{63}$ En latín en el original.

${ }^{64}$ En latín en el original.
} 
cerdos, y además va al mar, y captura estrellas de mar, cangrejos, etc. Tiene una crin de dos pies de largo, está recubierta de escamas, y tiene fieros ojos, perturba a los barcos, y se alza como un mástil, y algunas veces arranca a los hombres de la cubierta”. Hasta aquí este escritor, que, en el resto del capítulo, habla de la gran serpiente de agua en Miosen o Hedemarken, que predijo la muerte del rey y los grandes cambios que acaecerían cuando esto sucediera, de acuerdo con las supersticiosas creencias de esa época.

\section{Sección X. Concerniente a las grandes serpientes de otros países.}

Antes de dejar esta materia, puede ser apropiado responder a una pregunta que puede ser hecha por varias personas, a saber, qué razón puede explicar que esta serpiente de extraordinario tamaño, etc, solamente se encuentre en el mar del Norte.

El mar del Norte su lugar original. Porque, de acuerdo con todos los relatos de los marineros, nunca ha sido vista en ningún otro lugar. Aquéllos que han navegado en otros mares en diferentes partes del globo, en sus diarios han tomado noticia particular de otros monstruos marinos, pero ninguno menciona éste. A ello respondo, que cuando el asunto es confirmado por evidencia incuestionable, y se halla ser cierto, entonces esta objeción no requiere otra respuesta que el Señor de la naturaleza dispone los domicilios de sus varias criaturas en diferentes partes del globo, de acuerdo con sus amplios propósitos y designios. La razón de estas decisiones no puede, no debe ser comprendida por nosotros. ¿Por qué el reno no prospera en ningún otro clima, excepto en las frías y desoladas montañas del norte? ¿Por qué hace que la enorme ballena se mantenga solamente en estas heladas regiones contiguas al polo? O, ¿por qué son las Indias y Egipto los únicos lugares donde el cocodrilo muestra su odiosa forma, y aterroriza a los viajeros imprudentes? Ninguna otra razón puede ser señalada que ésta, a saber, porque el sabio Creador ha pensado que debería ser así, y cualquier cosa que desea es correcta, y dispuesta para lo mejor (208).

Grandes serpientes en otros países. Mientras estoy hablando de Egipto, recurriendo a la asociación de ideas, creo no haber leído de ninguna serpiente marina en esas partes del globo, a pesar de todo hallo que en Egipto y otros lugares de Africa se han encontrado en lagos de agua dulce y ríos una especie de serpientes casi tan largas como de las que estoy tratando, e incluso más peligrosas.

Plinio dice en su Hist. Nat. Lib. VIII. Cap. XIV. Megástenes escribe que en la India las serpientes crecen hasta un tamaño tan grande que devoran ciervos y toros enteros; Metrodoro, que en el Ponto, en torno al río Ríndaco, se tragan a las aves engulléndolas de un 
bocado aunque vuelen alto y rápido. Es famosa una serpiente de ciento veinte pies de longitud, que fue tomada por el general Régulo, como si se tratara de una ciudad, con ballestas y máquinas de asalto, en las guerras púnicas, junto al río Bagrada: su piel y sus quijadas permanecieron en un templo de Roma hasta la guerra de Numancia. Dan crédito a estos relatos las llamadas «boas» en Italia, que llegan a tan gran tamaño, que, en el principado del divino Claudio, fue encontrado un niño entero en el vientre de una, matada en el Vaticano. Se alimentan primero con la succión de leche de vaca, de donde les viene el nombre. De los demás animales que, llegados recientemente desde todas partes, han venido a Italia con mayor frecuencia, no es necesario describir con detalle la forma ${ }^{65}$.

Lo que aquí se cuenta, concerniente a una serpiente que fue muerta cerca del río Bagrada en Africa, parece casi increíble, aunque es confirmado por Livio en su 29 década, primi belli Punici, y por Valeriano Máximo lib. I cap. Ult. Uno apenas puede ser capaz de comprender o creer que una serpiente detuviera a todo un ejército romano, y disputara su paso, o que matara a muchas personas, las cuales, con sus mejores armas, apenas pudieran herirla, pero vemos en qué autoridades se sostiene. Todavía más extraña es la historia en la que Diodoro Sículo, lib. III, muestra una serpiente de Egipto de 60 pies de largo, aunque pequeña en comparación con aquéllas de las que hemos hablado, aparentemente era demasiado grande para ser capturada y llevada a Alejandría para ser presentada al rey Ptolomeo II.

Este gran príncipe era eminente por su curiosidad, y estaba deseoso de ver todas las cosas que fuesen extrañas o poco comunes. Aquéllos que le traían elefantes, o cualquier otro animal poco frecuente, eran liberalmente recompensados. Por este medio los griegos se familiarizaron con muchas cosas que antes eran absolutamente desconocidas para ellos. Tan laudable curiosidad, y tan noble espíritu en un rey, de recompensar a todos aquellos que contribuyeran a agradarle e instruirle, animó a un grupo de cazadores a intentar traerle la dicha gran serpiente, que vivía principalmente en el agua, pero que cada día se alejaba de su propio elemento a una considerable distancia (209) para hacer presa en el ganado de los granjeros para su subsistencia. Su primer ataque, que fue muy vigoroso, falló, como dicen los historiadores, y costó cerca de veinte de sus vidas, pero como los restantes ganaron más experiencia por estas pérdidas, no renunciaron a su empresa, estando en la esperanza de recibir una gran recompensa en caso de que tuvieran éxito. Finalmente la vencieron, por hacer una gran red de cuerdas muy fuertes, y esperando su oportunidad cuando la criatura

${ }^{65}$ En latín en el original. Traducción Plinio el Viejo, Historia natural libros VII-XI. Biblioteca Clásica Gredos, vol. 308. 
saliera en busca de presas, entonces le cortaron el camino que usualmente tomaba al regreso, e hicieron una especie de desfiladero a través del cual fuera obligada a pasar. $\mathrm{Al}$ final del mismo situaron la red, y condujeron al monstruo hasta ella. Cuando la hubieron asegurado, la llevaron ante el rey, que les dio una recompensa adecuada a la extrañeza de la criatura y el riesgo de su empresa. La serpiente fue conservada para ser vista por los extranjeros que visitaban la corte de Ptolomeo, y tenía diariamente una gran ración de comida apropiada. El autor concluye de esto lo que Odoard Dapper y otros escritores de fecha posterior confirman, a saber, que en Etiopía y otros lugares de Africa hay serpientes bastante grandes como para devorar no solamente bueyes, sino también los elefantes más grandes, por enroscarse entre sus piernas, y después de esto enredarse, y los dominan con facilidad.

\section{Sección XI. Del Kraken, Krabben o Horven, el mayor de todos los animales.}

Kraken o Korven, la mayor criatura del mundo. Voy ahora a la tercera e indiscutiblemente la mayor serpiente del mundo, es llamada kraken, kraxen, o algunos la nombran krabben, siendo esa palabra aplicada para referirse a la eminencia de esta criatura. Este último nombre parece en efecto mejor para concordar con la descripción de esta criatura, que es redonda, gruesa, y llena de brazos. Otros la llaman también Horven o Soe-horven, y algunos Ansker-trold. Entre los escritores extranjeros, tanto antiguos como modernos, de los que he tenido la oportunidad de consultar en esta materia, ninguno de ellos parece saber mucho sobre esta criatura, o al menos tener una idea justa de ella. Lo que dicen sin embargo sobre islas flotantes, como aparentan ser, (algo improbable que exista en el ancho y tumultuoso océano), se tratará después de ello, y se encontrará ser aplicable sin ninguna exageración a esta criatura, cuando primero haya dado alguna noticia acerca de ella. Esto haré de acuerdo a lo que me ha sido relatado por mis correspondientes, y lo que por otro lado he recogido por medio de una industriosa encuesta y examen de cada particular, concerniente a los informes que recibía. Todo esto, en comparación a la naturaleza y configuración desconocida (210) de la criatura, es muy breve para ser un relato completo, deficiente, y calculado más para mantener despierta que para satisfacer la curiosidad del lector. Bochart puede por consiguiente decir con razón en su Lib. I. cap. 6, con Opiano Halieut. Cap. I. In mari multa latent, esto es, muchas cosas están escondidas en los océanos. Entre las muchas grandes cosas que están en el océano, y ocultas a nuestros ojos, o presentes solamente ante nuestra vista durante unos pocos minutos, es el kraken. Esta criatura es la mayor y más 
sorprendente de todos los animales de la creación, y consecuentemente bien merece un relato de su naturaleza, acordando con el prudente juicio del Creador. Esto daré en el presente, y quizás mucha mayor luz a esta materia sea reservada para la posteridad, de acuerdo con las palabras de Sirach, Ecclesiastés “¿Quién le ha visto para que pueda describirle? ¿quién puede engrandecerle tal como es? Mayores que éstas quedan ocultas muchas cosas, que bien poco de sus obras hemos visto".Cap. XLIII, ver. $31,32^{66}$.

\section{Sección XII. Su descripción, de acuerdo con el testimonio de muchos testigos ocu-} lares.

Descripción. Nuestros pescadores unánimemente afirman, y sin la menor variación en sus relatos, que cuando se adentran varias millas en el mar, particularmente en los días cálidos de verano, y por su situación (que saben por tener a la vista varios puntos de tierra) esperan encontrar 80 o 100 brazas de profundidad, sucede que a menudo no encuentran más que 20 o 30, y algunas veces menos. En estos lugares generalmente encuentran gran abundancia de peces, especialmente bacalao y abadejo. Dicen que tan pronto lanzan sus sedales enseguida los alzan con los anzuelos llenos, por ello juzgan que el kraken está en las profundidades. Dicen que esta criatura causa profundidades poco naturales, y les previene de su encuentro. Estos pescadores están siempre contentos de encontrarlo, considerando que significa la captura de abundante pesca. Algunas veces veinte botes o más van juntos, y se mantienen en línea a una moderada distancia el uno del otro, y lo único que han observado es que, mientras la profundidad continúa siendo la misma, lo que saben por sus sondas, les parece tener menos agua. Si éste es el caso, parece que el kraken se dirige hacia ellos cerca de la superficie, y entonces no es momento de permanecer allí más tiempo, y se marchan tan rápido como pueden. Cuando han alcanzado la profundidad acostumbrada del lugar, y se encuentran fuera de peligro, tienden sus remos, y pocos minutos después ven este enorme monstruo saliendo de la superficie del agua (211) y se muestra allí lo suficiente, aunque su tamaño completo no aparece, el cual con toda probabilidad ningún ojo humano ha contemplado jamás (exceptuando los más jóvenes de la especie, de los que hablaré posteriormente). Su parte superior o posterior, que aparentemente parece ser de una milla y media inglesa de circunferencia (algunos dicen que más, pero yo elijo la menor para mayor certeza), parece a primera vista como un número de pequeñas islas, rodeadas de algo que flota y fluctúa como algas marinas. Aquí y allá una mayor protuberancia es vista como bancos

${ }^{66}$ En latín en el original. Traducción Biblia de Jerusalén. 
de arena, en los cuales varias clases de peces son vistos continuamente saltando hasta que ruedan en el agua desde los lados, y por último aparecen varios puntos brillantes, o cuernos que se vuelven más gruesos y más gruesos y se elevan sobre la superficie del agua, y algunas veces se mantienen tan altos como los mástiles de veleros medianos.

Parece que son los brazos de estas criaturas, y, como se ha dicho, si agarran al guerrero más grande, lo arrojarían al fondo. Después este monstruo ha sido visto en la superficie del agua un corto tiempo, y empieza lentamente a hundirse de nuevo, y entonces el peligro es tan grande como antes, porque la acción de este hundimiento causa un mar de fondo, como un remolino, que atrapa todas las cosas hacia abajo con él, como la corriente del río Male, que ha sido descrita en el lugar apropiado.

Como este enorme animal marino con toda probabilidad puede ser confundido con el pólipo, o con una especie de estrella de mar, como posteriormente será probado más plenamente, parece que las partes que son vistas surgiendo a su voluntad, y son llamadas brazos, son propiamente los tentáculos, o instrumentos de los sentidos, llamados cuernos tanto como brazos. Con éstos se mueven, e igualmente los usan en su alimentación.

Para este último propósito el Gran Creador ha dado también a estas criaturas un fuerte y peculiar olor, que puede emitir en ciertas ocasiones, y por su rastro engaña y atrae a otros peces para que se amontonen sobre él. Este animal tiene otra extraña propiedad, conocida por experiencia por un gran número de viejos pescadores. Ellos observan que durante algunos meses el kraken o krabben está continuamente comiendo, y otros meses siempre evacúa sus excrementos. Durante esta evacuación la superficie del mar está coloreada con el excremento, y aparece bastante espesa y turbia. Se dice que este barro es muy agradable al olfato y al gusto de otros peces, o ambos, así que se reúnen en torno a él, y se mantienen por este propósito directamente sobre el kraken, entonces él abre sus brazos, o cuernos, se apodera y engulle a sus bienvenidos invitados, y les convierte, después de su debido tiempo, por digestión, en un cebo para otros peces de la misma clase. Cuento (212) lo que es afirmado por muchos, pero no puedo dar seguridad cierta de este particular, tanto como sí puedo sobre la existencia de esta criatura, aunque no encuentro ninguna cosa en absoluto contraria a la naturaleza. Como difícilmente podemos esperar una oportunidad de examinar vivo a este enorme animal marino, el cual, de acuerdo con el siguiente relato, una vez lo hizo, y quizás nunca más pueda ofrecerse ocasión de observarlo por entero estando muerto. El reverendo Mr. Friis, asesor consistorial, ministro de Bodoen en Norland, me dio a finales de este año, cuando estaba en Bergen, esta relación, de cuyo crédito me fío.

En el año 1680 un kraken (quizás uno joven y descuidado) vino a las aguas que corren 
entre las rocas y acantilados de la parroquia de Alstahoug, aunque la costumbre general de esta criatura es mantenerse varias leguas lejos de tierra, y por lo tanto, por supuesto, ellos deben morir allí. Sucedió que sus largos brazos extendidos, o antenas, las cuales esta criatura parece usar como el caracol, girando alrededor, se agarró de algunos árboles permaneciendo cerca del agua, que puede fácilmente haber tomado por las raíces, pero además de esto, como fuera encontrada más tarde, él se enredó a sí mismo en algunas hendiduras o grietas en la roca, y entonces se quedó atrapado rápidamente, así que no pudo salir, sino que murió y se emputreció en el lugar. El cuerpo, que estaba bastante descompuesto, y cubría gran parte del estrecho canal, lo hizo casi intransitable por su intolerable hedor.

No se conoce que el kraken haya hecho alguna vez algún daño, excepto que ha tomado las vidas de aquellos que han sido llevados por la marea. Yo nunca he oído nada, salvo un suceso al respecto, que sucedió hace unos cuantos años cerca de Fridrichstad, en la diócesis de Aggerhuus. Dicen que dos pescadores accidentalmente, y para su gran sorpresa, cayeron en un lugar en el agua, tal como ha sido descrita antes, llena de un espeso barro, casi como un lodazal. Inmediatamente se afanaron por salir de ese lugar, pero no tuvieron tiempo de hacerlo rápidamente para salvarse de uno de los cuernos del kraken, que crujieron también la proa del bote, y que con gran dificultad salvaron sus vidas del naufragio, aunque el agua estaba tan calma como era posible, porque estos monstruos, como la serpiente marina, nunca aparecen en otras ocasiones (213).

\section{Sección XIII. Principalmente se confirma la verdad de su existencia, y explica algunos fenómenos oscuros.}

Aún más testimonios. He dado ahora inteligencia de lo que ha venido a mi conocimiento acerca de este enorme, pero hasta ahora escasamente conocido animal marino, y ahora relataré además, de acuerdo a lo que es más probable, algunas propiedades que se presume le pertenecen. Esto puede arrojar más luz sobre su historia, y también sirve como una mayor confirmación de lo que se ha dicho concerniente a él. Mr. Luke Debes, en su Description of Feroe, habla de ciertas islas que aparecen repentinamente, y que repentinamente se desvanecen. Esto era un asunto que nadie podía comprender, así que uno puede no maravillarse como el pueblo común, e incluso estar en desacuerdo con esto, por considerarse estas islas vivientes ser habitadas por espíritus diabólicos, que aparecen en algunos lugares donde los marineros, por experiencia diaria, saben muy bien que no había ni siquiera una roca, mucho menos una isla, pero sin embargo encuentran a menudo en el mar algo que tiene 
la apariencia de tierra, y consecuentemente son confundidos, hacen falsos cálculos y se apartan de su curso, lo que les trae graves inconvenientes ${ }^{67}$.

Una definición de islas flotantes. Muchos marineros aportan relatos de tales apariencias de tierra, y su repentino desvanecimiento, particularmente aquí en el mar del Norte. Estas islas, en el bullicioso océano, no pueden imaginarse ser de la naturaleza de las islas flotantes reales, que son vistas en aguas dulces y estancadas, y que he observado, p. I. c. 3, se encuentran en Noruega y en otras partes. Estas posiblemente no se sostienen o permanecen contra la violencia de las olas en el océano, que rompe los mayores barcos, y por consiguiente nuestros marineros han concluido que esta ilusión no podía venir de otra cosa más que del gran engañador, el diablo. Pero, de acuerdo con las leyes de la verdad, no podemos acusar a este espíritu apóstata sin una causa. Pienso mejor que este demonio, que repentinamente hace y deshace estas islas flotantes, no es más que el kraken, que algunos marineros llaman Soe-draulen, esto es, Soe-trolden, Sea-miswchief. Lo que me confirma en esta opinión es el siguiente suceso, anotado por ese loable médico sueco Dr. Urban Hierne ${ }^{68}$, en su Short Introduction to an Enquiry into the Ores and Minerals de ese país, p. 98, del Barón Charles Grippenhielm. La anotación (214) es como sigue: "Entre las rocas cerca de Estocomo se ha visto algunas veces un cierto tramo de tierra, que otras veces desaparece, y es visto de nuevo en otro lugar. Buraeus ha señalado esto en su mapa como una isla. Los lugareños, que la llaman Gumarsore, dicen que no se ve siempre, y que permanece en el mar abierto, por lo que nunca pueden encontrarla. Un domingo, cuando estaba entre las rocas sondeando la costa, sucedió que vi algo como tres puntos de tierra en el mar, que me sorprendieron un poco, y pensé que había pasado antes ante ellos. Tras esto, llamé a un campesino para preguntarle sobre el Gummars-ore, pero cuando llegó no pude ver nada de ello, a lo que el lugareño me dijo que era habitual, y que esto pronosticaba una tormenta o una gran cantidad de pesca". Hasta aquí Grippenhielm. Ahora bien, lo que no puedo dilucidar, a primera vista, es que este visible e invisible Gummars-ore, con sus señales y pronósticos de peces, no pueda ser posiblemente más que otra cosa que el kraken, krabben, o Soe-horven, impropiamente señalado por Buriaeus como una isla. Probablemente la criatura permanezca siempre alrededor del lugar, y a menudo se alce sobre las rocas y acantilados.

\footnotetext{
${ }^{67}$ Concerniente a las islas flotantes, veáse Everh. Harpelii. Mund. Mirab. Tom. I. Lib. IV. cap. 20, 21, y en Thormod. Torf. hay un remarcable testimonio de la misma clase, concerniente a una isla apareciendo en Breidefiord, en la costa de Islandia, Los anales registran que emergieron de las olas (año 1345) una especie de isla o bien unas rocas antes nunca vistas en el golfo Brediafiordo de Islandia. Hist. Norw. P. IV. L. ix. C. viii. p. 477. (En latín en el original). Es una lástima que él no nos diga si siempre se mantuvo allí (Nota del autor).

${ }^{68}$ Urban Hjärne (1641-1724), químico y geólogo sueco.
} 
Lo que el crédulo Olao Magno, en su Hist. Septentr. Lib. XX. Cap. 25 escribe $^{69}$, de la ballena tan grande que su dorso a menudo es visto como una isla, y que la gente puede desembarcar, hacer fuego, y varias clases de trabajo sobre ella, es notoriamente fabuloso y una historia ridícula. Sus palabras son "De ahí que con el dorso completamente elevado por encima de las olas los navegantes no la tienen por otra cosa que por una isla. Y así los marineros arriban a ella y ascienden por ella, clavan estacas, amarran las naves y encienden fuegos para cocinar alimentos. Hasta que finalmente la ballena, sintiendo el fuego, se sumerge en las profundidades etc. De vez en cuando levanta arena en su espalda, sobre la cual, cuando se desata la tempestad, reposan los marineros, echadas las anclas, con engañosa seguridad, contentos por haber encontrado tierra, mientras que la bestia, al sentir los fuegos encendidos, poniéndose de repente en movimiento, se sumerge y arrastra a las profundidades a los a los hombres con sus naves a no ser que se rompan las anclas" ${ }^{\text {"70 }}$. Podemos fácilmente ver que da gran ocasión de mezclar lo probable con lo improbable, por recoger lo que ha sido observado acerca del kraken, del cual la gente ha tenido una idea imperfecta en las edades pasadas.

No era enteramente desconocido para Plinio. Incluso Plinio, en su tiempo, había oído algún oscuro relato de un animal marino como el que aquí se trata. Esto se puede concluir de sus palabras en Lib. IX. Cap. IV. "Los animales de mayor tamaño en el mar Índico son la ballena y el pez sierra; en el océano Gálico, el cachalote, que se levanta a modo de una inmensa columna y poniéndose más alto que las velas de las naves eructa una especie de diluvio; en el océano Gaditano, el «árbol», que se expande hasta tal punto con sus anchas ramas (215) que se cree que precisamente por esta razón nunca había pasado el Estrecho. También existen las «ruedas», así llamadas por su semejanza con ellas; están divididas por cuatro radios tapando el cubo de la rueda por uno y otro lado sus dos ojos" ${ }^{\text {"71 }}$.

El doble relato que se proporciona aquí de una criatura que parece una ballena, separada en radios, o un árbol, con brazos tan largos que no puede atravesar un canal, parece concordar con lo que ya se ha visto del kraken, con sus muchos largos cuernos o brazos, brotando de su cuerpo que es redondo ${ }^{72}$. Ambas descripciones confirman mi anterior

\footnotetext{
${ }^{69}$ En realidad es el libro XXI de la edición romana de 1555, la referencia del capitulo es correcta.

${ }^{70}$ En latín en el original.

${ }^{71}$ En latín en el original. Traducción Plinio el Viejo, Historia natural libros VII-XI. Biblioteca Clásica Gredos, vol. 308.

${ }^{72}$ En el antiguo manuscrito llamado Speculum Regale, porque está dirigido al rey noruego Sverre, O. Wormius, que tuvo este tratado entre sus manos, encontró algunas cuantas palabras que parecían aludir a ella como la mayor criatura del océano, por cuanto en su Museum, p. 279, enumera las varias especies de ballenas, concluyendo, p. 280, con las siguientes palabras "Queda una especie, a la que llaman Hafgufe, cuyo tamaño se desconoce por ser raramente vista. Los que cuentan haber visto su cuerpo dicen que se parece más a una isla que a una bestia; y jamás se ha encontrado su cadáver, por lo cual hay quienes consideran que no hay sino dos de su género en
} 
suposición, a saber, que este animal marino pertenece a la especie de los pólipos o estrellas marinas, que han sido particularmente descritas en el capítulo precedente. Parece ser uno de esa clase de pólipos llamada por los holandeses Zee-sonne, por Rondelet ${ }^{73}$ y Gesner $^{74}$ Stella Arborescens, es decir, una estrella que muestra sus radios como brazos como los de los árboles, de acuerdo con la más exacta descripción referida, donde le doy el nombre de Cabeza de Medusa.

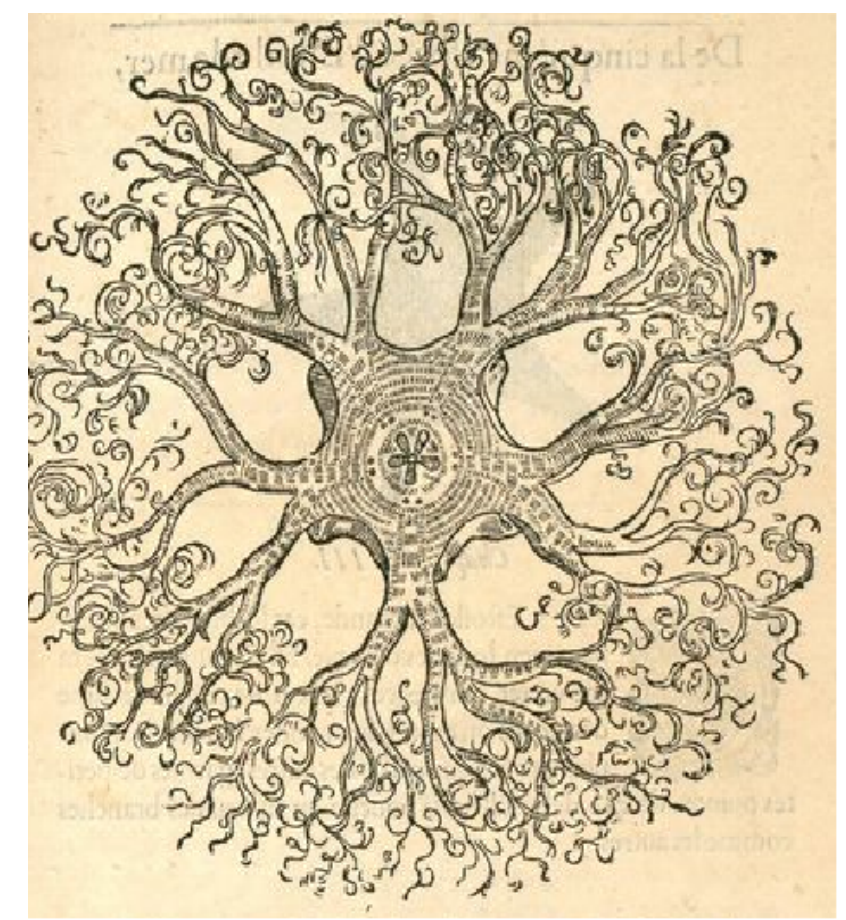

Imagen 5. Estoile de mer croissante en arbre, en Guillaume Rondelet, Histoire entiere des poissons, seconde partie, Lyon, 1558, p. 83.

https:/ $/$ books.google.es/books?id=lB8OAAAAQAAJ\&printsec $=$ frontcover\&dq= rondelet + histoire + entiere + des + poissons\&hl $=$ es\&sa $=$ X\&ved $=0$ ahUKEwig6cn-

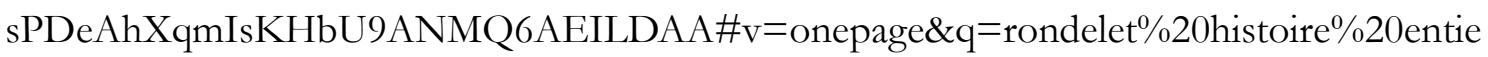
re $\% 20$ des $\% 20$ poissons\&f $=$ false

Lo que he observado además es que esta especie de estrella marina, con sus muchos brazos o radios, es muy apta para agarrarse, y se enredan en los hierbajos y arbustos que crecen en el fondo del mar, y a menudo son alzadas por los pescadores. Cuando están secas, y sus brazos encogidos, muy pocas veces tienen más de seis u ocho pulgadas de

\footnotetext{
la naturaleza" (En latín en el original)(Nota del autor). El Speculum Regale fue editado por Laurence Marsellus Marson con el título The King's Mirror (Nueva York, The American-Scandinavian Foundation, 1917). En las páginas 119 y siguientes habla de las ballenas de Islandia, en la página 125 encontramos una referencia al kraken. ${ }^{73}$ RONDELET, Guillaume, Histoire entiere des poissons, seconde partie, Lyon, 1558, p. 83.

${ }^{74}$ GESSNER, Konrad, Historiae animalium lib. IV. Piscium et aquatilitum animantium natura, Zurich, 1558, p. 1104.
} 
diámetro, pero cuando son sacadas del agua son mucho más grandes. Una persona muy digna me dijo que tenía algunas de una extraordinaria grandeza, y que ha visto otras cuatro veces más grandes del tamaño ordinario, chapoteando en el agua con sus numerosos brazos.

Estas Cabezas de Medusa, se supone, por algunos marineros de aquí, ser el joven de la gran serpiente marina, quizás son sus óvulos más pequeños, y yo no dudo que sea la misma Cabeza de Medusa, o Stella Arborescens, de la que Mr. Griffith Hugues trata en las Philosophical Transactions $^{75}$. Este acaba de venir a mis manos, y lo insertaré e igualmente lo añadiré, a lo que ha sido anotado en el capítulo precedente. "Se ha descubierto una nueva especie de estrella de mar, la cual sale de la roca por una especie de pedicula, y ella se asemeja exactamente a la figura rayada de la flor de una ficoide. Pero esta flor es (216) casi siempre sensitiva. Al menor toque se repliega, y se esconde con sus pedÍcula en las rocas, de donde había salido. Sus radios hacen de brazos, que tienen el aspecto de los de un pólipo. Qué gusto para un físico, que el de poseer un pólipo de esta grandeza, y qué observaciones no serían hechas sobre el crecimiento y la reparación de sus partes" ${ }^{\prime 76}$. Biblioth Raisonee, T. XXXVII, p. 266 ${ }^{77}$. Sin embargo, esto puede ser una verdad incuestionable, que ciertas clases de pulpos ${ }^{78}$ crecen hasta un tamaño monstruoso. Athanasius Kircher dice, en su Mund. Subterran. P. I. p. $99^{79}$, que en los mares de Sicilia se ha encontrado una especie de estrella marina, que tiene diez radios, o brazos, y un cuerpo tan grande como el de un hombre, pero esto no resiste la proporción con la grandeza de una ballena, que Athenaeus, in Lib. XIII.cap. VI atribuye a algunos de ellos. Plinio, lib. IX, cap. XXX, habla de una especie de pulpo de un monstruoso tamaño, con el nombre de Ozaena ${ }^{80}$, porque desprende un fuerte olor, por cuya razón otros peces les siguen. Esta singularidad concuerda exactamente con lo que ya se ha dicho del kraken noruego, "Todas las criaturas marinas atraídas enormemente por su olor" ${ }^{81}$.

\footnotetext{
75 "A letter from the Rev. Mr. Griffith Hughes, Minister of St. Lucy's Parish in Barbadoes, to Martin Folkes, Esq; Pr. R. S. concerning a Zoophyton, somewhat resembling the Flower of the Marigold", Philosophical Transactions, XLII, 471, 1743, pp. 590-593.

${ }^{76}$ En francés en el original.

77 Bibliothèque raisonnée des ouvrages des savans de l'Europe, editado en Ámsterdam entre 1728 y 1753.

78 Traducimos el original inglés polype como pólipo, y polypus como pulpo, aunque, obviamente, el empleo de uno u otro término provoca que la naturaleza del kraken cambie por completo. Si nos vamos al $A$ Dictionary of the English Languaje de 1755 (consultada sexta edición de 1785), de Samuel Johnson, veremos que polypus significa "any thing in general with many roots or feets", o bien "a sea animal with many feets", en tanto polype no aparece. Ambos términos debían confundirse, ya que en las Philosophical Transactions encontramos un artículo titulado Some Account of the Insect Called the Fresh-Water Polypus (vol. XLII, 1742, pp. 422-436), que se refiere, naturalmente, a lo que en español entendemos como pólipo.

${ }^{79}$ KIRCHER, Athanasius, Mundus subterraneus, Ámsterdam, 1665.

${ }^{80}$ En verdad tiene un olor bastante intenso. Por ello los griegos lo llaman machitis y los napolitanos, en este siglo,

"muschardinus". Jacobus Dalecampis in Notis ad Plin. L. cit. (Nota del autor).

${ }^{81}$ En latín en el original.
} 
Concerniente a dicho pulpo Plinio relata en el mismo lugar, de acuerdo al relato que había recibido de L. Lucullus, el proncónsul de la Bética, algunas extrañas historias acerca de su fuerza y tamaño, como que permanecen junto a la costa, donde roban las mercaderías, y las toman con sus largas garras, así que ellos se ven obligados a situar perros junto a ellas, pero estos animales no pueden soportar el fuerte olor, y son también severamente dañados por las criaturas, y que con gran dificultad se las mataba con tridentes. "Espantaba a los perros con su bufido terrible, azotándolos, además, unas veces con las puntas de sus tentáculos, o golpeándolos otras veces con la parte más fuerte de sus brazos a modo de mazas; a duras penas se pudo acabar con él tras múltiples arponazos" ${ }^{82}$. Concluimos de todo esto, que el pólipo, o estrella de mar, o lo que llamamos aquí, la clase entera de Kors-Trold, tiene, entre sus varias especies, algunas que son más grandes que otras, y, de acuerdo a todas las apariencias, incluso que los mayores habitantes del océano. Si la afirmación es cierta, que la grandeza o pequeñez no provoca cambios en las especies, entonces el kraken debe ser de la clase de los pulpos, a pesar de su enorme tamaño. Todo lo que tengo que añadir a esto, que da crédito a la vieja opinión vulgar concerniente a un pez que tiene el poder de parar un barco en plena navegación, podemos concluir que es imposible porque sería ese pequeño pez, al que las fábulas llaman rémora, y que no es mayor que un arenque (217). Yo tengo uno de éstos en mi colección, tiene una dureza en la cabeza, algo como una lima, y algunas personas son tan simples de imaginar que esta diminuta criatura puede realizar la extraordinaria operación arriba mencionada.

El erudito jesuita Gasp. Schottus, en su Physica Curiosa ${ }^{83}$, ha examinado cuidadosamente la naturaleza y la probabilidad de este relato, y ha refutado por completo al docto Kirchner en este punto. Entre otras razones que son dadas para detener un barco en su recorrido en mitad del océano a aquéllos que navegan con un buen viento, lo que es un hecho innegable, considera un buen motivo la confluencia de ríos de varios lugares luchando juntos. Esta opinión tiene alguna probabilidad, y ese extraño efecto es realmente debido a esta causa en algunos lugares, pero, sea como sea, soy proclive a creer que el Kors-Trold, o SoeDrawl, así llamado por los marineros, los cuales lo consideran un espíritu diabólico, no puede ser más que el kraken, el cual, de acuerdo con la descripción dada arriba, parece ser capaz, con sus brazos o cuernos, de provocar este extraño efecto. Por lo tanto, quizás, es llamado, entre muchos otros nombres, como Anker-Trold, aunque no persisto en considerar esta

\footnotetext{
82 En latín en el original. Traducción Plinio el Viejo, Historia natural libros VII-XI. Biblioteca Clásica Gredos, vol. 308.

${ }^{83}$ Kaspar o Gaspar Schott (1608-1666), jesuita alemán autor de Physica curiosa (1662).
} 
conjetura cierta, pero de buena gana someto mis suposiciones en esto, y en cualquier otra materia dudosa, al juicio de aquéllos más experimentados. Si fuera un admirador de ciertos relatos, y fabulosas historias, podría añadir aquí mucho más concerniente a esto y a otros monstruos marinos noruegos, cuya existencia no llego a negar, pero no elijo, por una mezcla de relaciones inciertas, hacer que algunos relatos aparezcan dudosos, si yo mismo no creo ser ciertos y bien atestiguados. Por lo tanto abandonaré la materia aquí, y dejo a futuros escritores este proyecto, para completar lo que imperfectamente he esbozado, por nuevas experiencias, que es siempre el mejor maestro (218). 